PHILOSOPHICAL TOPICS

VOL. 34, NOS. 1 \& 2, SPRING AND FALL 2006

\title{
Kant and the Problem of Experience
}

\author{
Hannah Ginsborg \\ University of California, Berkeley
}

As most of its readers are aware, the Critique of Pure Reason is primarily concerned not with empirical, but with a priori knowledge. For the most part, the Kant of the first Critique tends to assume that experience, and the knowledge that is based on it, is unproblematic. The problem with which he is concerned is that of how we can be capable of substantive knowledge independently of experience. At the same time, however, the notion of experience plays a crucial role in the central arguments of the Critique. For, again as most readers of the Critique know, Kant aims to show how we can have synthetic a priori knowledge by showing that the categories, or pure concepts of the understanding, are conditions of the possibility of experience. This means that, whether or not Kant is concerned with the notion of experience for its own sake, his account of a priori knowledge carries with it at least some commitments regarding the character of experience. If the account of a priori knowledge is to be successful, then experience has to be the kind of thing for which the categories can, in principle, serve as conditions of possibility. More specifically, experience must involve not only the senses, but also thought or understanding, for otherwise the claim that it presupposes a certain specific set of concepts is simply unintelligible. And indeed at least some parts of the Critique, in particular the so-called subjective deduction in the first edition, and the briefer passages which correspond to it in the second edition, seem to be intended to show how this requirement is met. That is, they are concerned not so much with showing that experience is governed by the categories, as with elaborating a view of experience as involving conceptual activity überhaupt. 
If Kant's project in the Critique of Pure Reason is to succeed, then, it must be possible to arrive at a coherent interpretation of his notion of experience. But as I shall go on to argue, this is very hard to do. The idea that experience involves the activity of understanding raises a large problem, which can be put formulaically in terms of an apparent conflict between the "spontaneity" characteristic of understanding, and the "receptivity" characteristic of sense perception. How can experience involve the activity of thinking or judging, while still being a means through which objects can be "given" to us? While some aspects of this problem have indeed been directly addressed in the secondary literature in Kant, the fact that Kant's own focus in the Critique is on a priori rather than empirical knowledge has meant that the problem as a whole is often either ignored, or touched on only in passing. ${ }^{1}$ Yet to the extent - and I think it is a large one — that Kant's views on the possibility of a priori knowledge depend on the coherence of his account of experience, it is important for understanding his avowed project that we have a clear grasp of the problem facing that account. My main aim in this paper, then, is to articulate the problem and to give a sense of its pervasiveness. I show first, in sections I-II, how the problem impinges on various traditional interpretations of Kant's notion of experience, and then go on in section III to consider, and offer reasons for rejecting, a less traditional solution to the problem offered by John McDowell. But while my primary concern is to clarify the problem and to show that it presents a genuine threat to the coherence of Kant's view, I end on a more constructive note in section IV by sketching, very briefly, an alternative approach with what I hope are better prospects for overcoming it.

I.

In the passage from the second edition preface where he compares his approach to a priori knowledge with the Copernican hypothesis in astronomy, Kant says that "experience itself is a kind of cognition which requires understanding" (Bxvii). ${ }^{2}$ This conception of experience, he makes clear, is crucial to showing how objects given in experience can be known by us a priori. For as he goes on immediately to explain, understanding has "a rule which I must presuppose a priori in myself even before objects are given to me" (ibid.) and which, he says, is expressed in a priori concepts with which the objects of experience must necessarily agree. If experience requires understanding, then it must be governed by the a priori rules to which the understanding is subject, and consequently the objects given to us in experience must conform to concepts which express those rules.

The idea that experience requires understanding is rightly regarded as a fundamental insight of Kant's view. But its centrality to Kant's thinking, and its consequent familiarity to Kant scholars, should not blind us to a seeming paradox it presents. On the one hand, the understanding is characterized by Kant as a capac- 
ity for making judgments: "we can reduce all acts of the understanding to judgments, so that the understanding in general can be represented as a capacity for judging [Vermögen zu urteilen]" (A69/B94). Having experience, then, would seem on the face of it to be a matter of making judgments; something which Kant makes explicit when he notes, on his copy of the first edition of the Critique, that "experience consists of judgments" (23:24-25, reprinted in Kant 1998, 202). And in making a judgment one is, again on the face of it, active as opposed to passive, or in Kant's terms spontaneous as opposed to receptive: one is not merely receiving an impression from the world, or having the world affect one in a certain way, but rather committing oneself to, or taking a stand on, the world's being a certain way. But, on the other hand, the notion of experience is often seen as contrasting with that of judgment, and, correspondingly as connoting a state in which one is passive or receptive as opposed to active or spontaneous. Experience, at least in the sense associated with the empiricist tradition, is the means through which we are confronted with the objects about which we make judgments. ${ }^{3}$ Objects are given to us in experience, and while experience can thus serve as a basis for forming a judgment about how those objects are, that judgment involves an active exercise of mind which goes beyond the mere reception of data which characterizes experience itself. To the extent, then, that Kant intends to maintain this traditional conception of experience, it is hard to see how he can also take it to require understanding. For that would seem to imply that experience involves actively committing ourselves to how things are, as opposed to passively registering impressions which might or might not serve as a basis for committing ourselves through an act of judgment.

A straightforward approach to this apparent paradox is to deny that Kant's use of the term experience, at least in the relevant context, is intended to mark a continuity with the notion of experience as understood by the empiricists. Experience should not be identified with the perceptual impressions through which objects are given to us but rather with the empirical judgments we make on the basis of these perceptual impressions. In other words it should not be identified with what we might intuitively think of as my "perceptual experience" of, say, a green cube in front of me-the visual impression which is made on me by the green cube-but rather with the perceptually based judgment or recognition that there is a green cube in front of me. Thus when Kant says that experience requires understanding, he is making the relatively uncontroversial claim that our empirical judgments require understanding, and not the more radical claim that we require understanding in order for objects to be presented to us perceptually. An approach of this kind might be supported by appeal to Lewis White Beck's distinction between two senses in which Kant uses the term "experience," one corresponding to what Beck calls "Lockean experience" or "L-experience," the other corresponding to "Kantian experience" or "K-experience." L-experience is "the raw material of sensible impressions,' the manifold of apprehensions or Lockean ideas without the conceptual and interpretative activities of the mind" $(1978,40)$. But K-experience is "knowledge of objects" (ibid.), and it is this experience, rather than L-experience, which is governed 
by the categories and which, a fortiori, requires understanding. Now while Beck himself equates K-experience with "knowledge" rather than "judgment," it is at least a consequence of the distinction that experience in the full-blooded Kantian sense is a matter of making judgments as opposed to receiving sensory impressions, and that it is only for experience so conceived that the understanding is required. And the contrast between K-experience and "Lockean" ideas makes explicit that the notion of experience in this full-blooded Kantian sense is not intended to be continuous with that of perceptual experience as understood by the empiricists.

But there are a number of considerations that make this approach unattractive. Perhaps the most significant is that it threatens to trivialize Kant's central project in the Critique, or at least to diminish its interest and importance. ${ }^{4}$ Kant's argument that the categories are conditions of the possibility of experience would be disappointingly limited in scope if it could show only that the categories were required for empirical thought and judgment, and not for the perceptual experience on which empirical judgments are based. Intuitively, the appeal of Kant's argument is that it promises to show not only that we need certain a priori concepts in order to think about the objects presented to us in perception, but that these concepts somehow have applicability to those objects independently to, and prior to, our forming judgments about them. If the argument is to retain this appeal, it must show the categories to be required not only for us to be able to make the judgment that, say, there is a green cube in front of us, but for us so much as to have the experience through which the green cube is given to us. For otherwise Kant seems to lack any justification for claiming that the categories have application to the green cube itself - that the green cube is a substance enduring through time and standing in causal relations-as opposed to claiming merely that they are a subjective condition of our being able to make judgments and entertain thoughts about the green cube.

Some commentators have claimed that Kant does not in fact want to argue that the categories apply to objects merely insofar as they are perceptually given to us. The best evidence for this claim is a passage from a section of the Critique that is intended to set up the problem that the Transcendental Deduction is supposed to address. Here Kant describes a "difficulty" in showing that the pure concepts necessarily relate to objects, a difficulty which arises because "objects can ... appear to us without necessarily having to be related to functions of the understanding, and therefore without the understanding's containing their conditions a priori" (A90/ B122): appearances, he goes on to say, "could after all be so constituted that the understanding would not find them in accordance with the conditions of its unity" (A90/B123). Kant seems here to be denying quite categorically that the categories, and $a$ fortiori understanding, are required in order for objects to be perceptually given to us. And if this denial is taken at face value, then there is no reason to take understanding to be required for anything more than empirical judgments about the objects that are perceptually given to us; certainly there is no need to suppose that perceptual experience, conceived as prior to such judgments, also involves the understanding. ${ }^{5}$ 
However, the context suggests that this passage is not to be taken as representing Kant's considered view, for he goes on to say that, if appearances were so constituted, then "everything would lie in such confusion that, e.g. in the succession of appearances nothing would offer itself that would furnish a rule of synthesis and thus correspond to the concept of cause and effect, so that the concept would therefore be wholly empty, null, and without significance" (ibid.). And this would appear to be just the kind of possibility that the Deduction is supposed to rule out. The idea that Kant eventually means to deny the possibility described in the passage is confirmed by the argument at $\$ 26$ of the Deduction, which, for all its obscurity, does seem intended to show that whatever is given to us as part of a unified spatiotemporal manifold must necessarily be subject to the categories. ${ }^{6}$ And this in turn seems to suggest that, at least to the extent that the objects of our perception are perceived as standing in spatial and temporal relations to one another, the understanding is required for perceiving them, and not just for making judgments about them.

A closely related reason for rejecting what I am calling the "straightforward" approach is that Kant's account of the "synthesis of imagination" in both editions of the Critique seems intended to make the point that synthesis or combination is required not just for what we would pretheoretically describe as making judgments about the world, but for the mere perception or apprehension of it. The point is brought out, for example, in Kant's remark that psychologists have not yet recognized-Kant, himself, by implication, being the first to do so- "that imagination is a necessary ingredient of perception itself" (A120n.). In order for us to have perceptual images of objects, "something more than the receptivity of impressions is required, namely a function for the synthesis of them" (ibid.). And while Kant tends to be less explicit about this in the first than in the second edition, his considered view seems to be that all synthesis or combination, even that which is in the first instance ascribed to the imagination, is governed by the understanding: "the combination [Verbindung] (conjunctio) of a manifold in general can never come to us through the senses ... for it is an act [Aktus] of the spontaneity of the power of representation, and, since the latter must be called understanding, to distinguish it from [zum Unterschiede von] sensibility, all combination, whether we are conscious of it or not, whether it is a combination of the manifold of intuition or of several concepts ... is an act of the understanding [Verstandeshandlung], to which we would assign the general title synthesis" (B130). It is, as he puts it in a note to $\$ 26$, "one and the same spontaneity which, there [viz., in the synthesis of apprehension] under the name of imagination, and here [viz., in the synthesis of apperception] under the name of understanding, brings combination into the manifold of intuition" (B162n.). And it is in part by identifying the activity of imagination in perception with the spontaneity of understanding that he is able to claim, in concluding the argument of the Deduction at $\$ 26$, that "all synthesis, even that through which perception itself becomes possible, is subject to the categories" (B161). ${ }^{7}$ Thus Kant specifically does not want to say that the role of the categories, and more generally the understanding, is restricted to what we would pretheoretically 
regard as the making of a judgment as opposed to the having of a perception; rather, understanding is required for perception itself. To return to our example, the exercise of understanding is required not just for my judgment that there is a green cube in front of me, or that the cube in front of me is green, but for the very perception through which the green cube is presented to me. And this point seems intended on the face of it to cut against the empiricist view that I can come to have ideas of color and shape, and more generally perceptual images, through the operation of my sensory faculties alone.

II.

I have been arguing so far that Kant's claim that understanding is required for experience is not just the uncontroversial claim that we need understanding in order to make empirical judgments, but the more radical claim that we need it to have the kind of experience that, in the empiricist tradition, was given to us by the senses alone. If this argument is correct, then we must reject what I am calling the straightforward approach to the seeming paradox. We cannot take Kant simply to mean by "experience" what we traditionally think of as empirical judgment or knowledge in contrast to perceptual experience. But we might now consider an alternative approach which begins by granting that "experience" in the relevant sense is indeed supposed to capture a notion that is at least to some extent continuous with the empiricist conception of experience, but which interprets the role of understanding within experience as different from the role that it plays in making judgments in the traditional sense. On this more nuanced approach, there are two different ways in which the understanding can operate, one in which it is responsible for making explicit judgments, the other in which it is responsible for the constitution of perceptual experience. Béatrice Longuenesse articulates a version of this approach when she distinguishes "two aspects of the activity of understanding" $(1998,63)$. On one aspect, that corresponding to the activity of understanding within perception, "the understanding is a rule giver for the syntheses of imagination.... In this first aspect the activity of the understanding, or actualizing of its rules, is nothing else than productive synthesis of imagination" (ibid.). By contrast, "[a]ccording to the second aspect, the understanding is reflective or discursive. It reflects sensible syntheses"- that is, the syntheses for which understanding in its first aspect has prescribed the rules- "under concepts, whether empirical or pure" (ibid.). Longuenesse goes on to connect this contrast with one marked by Kant in a passage from $\$ 15$ which I quoted above to support the argument against the straightforward approach. Kant notes there that "all combination ... whether it is a combination of the manifold of intuition or of several concepts ... is an act of the understanding" (B130, my emphasis). Understanding under its first, experiential, aspect is responsible for the combination or synthesis of the manifold of intuition; 
but under its discursive aspect it is responsible for the combination of concepts through which we make judgments in the traditional sense. ${ }^{8}$

On this kind of approach, Kant's view avoids the threat of triviality which arises if we simply take him to redefine experience as meaning empirical judgment or empirical knowledge. For it allows experience to be understood as contrasting with, and as potentially providing a ground for, empirical judgment in the ordinary sense. It thus allows us to give some anti-empiricist substance to the claim that experience requires understanding, and hence is governed by the categories. Experience on this view can indeed be described as involving a kind of judging activity, so that justice can be done to Kant's remark, quoted earlier, that "experience consists of judgments." Paton, for example, makes room for this possibility when he articulates a distinction analogous to Longuenesse's but describes it as contrasting, not two aspects of understanding, but rather "two quite different aspects or implications of judgment" (1936, vol. 1, 265). ${ }^{9}$ But the kind of judging involved is, we might say, intuitive rather than discursive, and results in an experience of objects' being a certain way, rather than in a commitment to the claim that they are that way. And there is a recognizable continuity between experience, construed as involving this kind of judgment or activity of understanding, and experience in the empiricist sense.

Now it is true that this approach must also make room for purely sensible impressions which do not presuppose the activity of the understanding in any sense: namely, the manifold of empirical intuition which is combined or synthesized by the imagination under the direction of the understanding. So one might worry that there is still a threat of triviality in Kant's position. To show that the categories are not just conditions of our thinking and judging about objects, but that they apply to the objects that are perceptually given to us in advance of our thinking about them and judging them, wouldn't Kant need to perform the apparently impossible task of showing that this unconceptualized sensory manifold itself cannot be taken in by us except through an activity of understanding? Or, to put the worry another way, isn't it the unconceptualized sensory manifold, rather than the "experience" arising from the imagination's combination of the manifold, that should be identified with experience in the sense assumed by the empiricists? A natural answer, on this approach, is that the unconceptualized sensory manifold on its own, while it might in a thin sense "give us" objects, still falls short of perceptual experience as the empiricists understood it. Locke and Berkeley, for example, assumed that our sensory ideas present us not only with particular individuals, but also with determinate qualities possessed by those individuals, such as shapes and colors. When our vision is affected by a green cube, on their model of perception, we see something as having a particular shape and shade of color. Something beyond mere sensory receptiveness might admittedly be needed, on their model, to see whatever is presented as, say, a three-dimensional cube, rather than as a pattern of shapes and colors in the visual field; and arguably sensory receptiveness might not be sufficient for us to see what is presented as having the general color green, rather 
than as being some specific shade of green, or to distinguish the idea of the presented color from that of the presented shape. But there is nonetheless something quite determinate in the sensory given assumed by the empiricists: something which allows us to note resemblances among different items presented to us, and to recognize any one item as having this or that in common-at least as regards simple sensory qualities like color and shape-with this or that other item. ${ }^{10}$ This sensory given can thus serve as a basis both for arriving at ideas of more complex qualities, and for making judgments about how such qualities are related to one another.

By contrast, on the answer I have just been sketching, the unconceptualized manifold of intuition in Kant's account does not acquaint us with features or aspects which different objects have in common. We might put this point by saying that it might indeed present us with an individual green cube, but without presenting it as green or as a cube; and, more minimally, it does not so much as enable us to see what is presented as having this or that particular shade of color, or as occupying a region of the visual field with this or that particular shape. So conceived, unconceptualized intuitions do not even rise to the level of data on which a possible judgment can be based. Intuitions without concepts are, as Kant's famous phrase has it, "blind" (A51/B75). ${ }^{11}$ It is not until the manifold has been synthesized by imagination, under the direction of understanding, that we arrive at something corresponding to the ideas that the empiricists ascribed to the senses alone. Thus, even though his position makes room for unconceptualized sensory impressions prior to any activity of understanding, Kant can still be understood as holding, as Longuenesse puts it, that "the psychological data empiricists assume depend themselves on operations empiricists cannot account for" $(1998,38)$.

A natural way to think of the activity of perceptual synthesis on this more nuanced approach is as a kind of image formation under the guidance of rules which can be identified with, or at least which correspond to, concepts of what the image is to represent. ${ }^{12}$ We can think of this image formation, Kant suggests, as a kind of "drawing": he says, for example, that "when I make the empirical intuition of a house into perception through apprehension of its manifold ... I as it were draw [zeichnen] its shape" (B162) and that "the concept dog signifies a rule in accordance with which my imagination can trace [verzeichnen] the shape of a four-footed animal in a general way" (A141/B180).$^{13}$ The resulting perceptual image, on this view, is one which represents its object as having a feature corresponding to the rule. When I apprehend a dog, I form an image of it in accordance with the rule or concept $d o g$, and thus come to see what is given to me as a dog. ${ }^{14}$ But the analogy has its limitations, given that if we are to think of perceptual synthesis as the formation of an image under the guidance of a rule, we have to consider the image as formed out of sensory impressions which are given prior to the activity of synthesis. ${ }^{15}$ Synthesis appears, at least on the face of it, to be a process of combining or putting together sensory elements which constitute the "raw material" of experience (A1, B1). So the question arises, as it does not in the case of drawing a picture, 
of what the relation is between these sensory elements and the rules according to which imagination combines them. What determines which rules the understanding prescribes for the synthesis of a given sensory manifold? And in particular, what role does the manifold itself play in dictating the rules by which it is to be synthesized?

In the case of the pure concepts of the understanding, the answer seems relatively clear. The understanding alone is the source of these rules, and since any sensible manifold must be synthesized in accordance with these rules, no question arises of which of the pure concepts in particular is to guide the synthesis of this or that collection of sensory elements. But, as the example of the dog in particular suggests, perceptual synthesis is guided not only by pure, but also by empirical, concepts. Pure concepts alone could not direct my imagination to synthesize the sensory material into an image which represents what is given to me as a dog rather than, say, as a table. What is needed if my imagination is to form an image of a dogthat is, an image which represents its object as a dog —is that I synthesize the manifold according, precisely, to the concept $\operatorname{dog} .{ }^{16}$ But we might now ask, what makes it the case that when, say, my senses are affected by a dog, my understanding directs my imagination to synthesize my sensory impressions according to the concept $d o g$ rather than according to some other empirical concept? And here we might have in mind two distinct, but related, questions. We might ask why, in general, the understanding prescribes some rules of synthesis rather than others: why, for example, it directs the imagination to synthesize according to the rules dog or green as opposed to any of the infinite number of their grue- and quus- like competitors (say dog that is not under the Eiffel Tower or green and opaque or blue and translucent). ${ }^{17}$ Alternatively, we might set aside the question of what determines the stock of empirical rules available to direct perceptual synthesis, and just ask what it is which determines that one rather than another of these rules is employed on a particular occasion. Suppose that my senses are affected by a green cube: granted that the concepts available to guide my synthesis are green and blue rather than grue and bleen, what directs my imagination to synthesize these intuitions according to the green rule as opposed to the blue rule?

It seems obvious that, if the approach under discussion is to do justice to the receptive aspect of experience, then the answers to both these questions must make reference to the sensory manifold. Even if it is understanding which is, in Longuenesse's terms, the "rule giver" for synthesis, the sensory manifold must play a role in determining both which rules are prescribed in general, and when one rule is to be applied in preference to some other. ${ }^{18}$ When it comes to the formation and application of empirical concepts, understanding must, so to speak, borrow its authority from sensibility. For otherwise there would seem to be no sense in which sensible intuition could determine the content of perceptual experience, and hence no sense in which it could serve as its "matter." Sensible intuition would present me only with an indeterminate "this," with no indication of how it was to be combined with other such "this-es": the responsibility for my seeing what was presented to me 
as having one feature rather than another, as green rather than blue (or grue), or as a cube rather than a sphere (or a sphube) would lie solely with understanding. ${ }^{19}$ But now the approach faces a difficulty. If it is allowed that the sensory manifold plays a role in determining the rules for how it is, itself, to be synthesized, then it is hard to see how sensible intuition can count as "blind" in the sense characterized above. To put the difficulty crudely, how can a given sensory manifold convey to understanding that it is to be synthesized according, say, to the rules green and cube, without thereby already representing the item it presents as green or as a cube? If in receiving sensible intuitions, we already receive a specification of the ways in which those sensible intuitions are to be combined, then it looks as though the sensory manifold is presented to us, prior to any activity of imagination under the guidance of understanding, with no less determinateness than, say, the sensory ideas of the empiricists. And then the worry about reemerges. For it now looks as though we can after all have experience, in something like the sense assumed by the empiricists, without any need for understanding.

The difficulty can also be put by noting that, if sensible intuitions are to determine the empirical rules by which they are synthesized, then it would seem that they have to play some kind of rational or justificatory role with respect to the activity of understanding within experience. We noted earlier that, on the approach we are considering, understanding's prescription of rules for the imagination can be treated as a kind of judging. But in contrast to the straightforward approach to the apparent paradox, the "judging" that takes place in experience is not to be assimilated to the making of judgments in the ordinary discursive sense. In particular, rather than being based on or grounded in experience, it serves to constitute the experiences which in turn serve to justify empirical judgments as ordinarily conceived. However, once we allow that unsynthesized empirical intuitions can determine what rules the understanding ought to apply in order to synthesize them, we are in effect considering them as standing in a rational or justificatory relation to the understanding's act of prescribing the rule. To say that the empirical intuitions I receive when I perceive a green cube determine that my understanding is to prescribe the rules green and cube for their synthesis is tantamount to saying that those empirical intuitions justify or rationalize the judgment that what is given to me is green, or is a cube. And this is, in effect, to undermine the distinction between the "nuanced" approach, as I shall now refer to it, and the more straightforward approach to which it was supposed to provide an alternative. Once we concede that the authority of understanding, in its "giving the rule" to imagination, is borrowed from the sensible intuitions which imagination synthesizes, then we are conceiving the activity of understanding as like the activity of judgment in the traditional sense, that is, a matter of making judgments about how things are on the basis of how they are presented to us in sensory perception. And again this opens Kant's view to what I have called the threat of triviality: the categories turn out to be conditions of thought and judgment, but there is no longer any reason to claim that they apply to the perceptual experience on which our judgments are based. ${ }^{20}$ 
There are a number of ways in which one might try to defend the nuanced approach against this line of objection. One is to allow that synthesis is not needed in order for us to be acquainted with simple sensory qualities like color and shape (perhaps more specifically restricted to two-dimensional shape); rather, its role is to make possible the representation of higher-level features like the property of being a dog or a house. This defense concedes, in effect, that unsynthesized sensible intuitions already possess the level of determinateness characteristic of Lockean simple ideas; synthesis is needed, not to make these ideas possible, but rather to allow us to organize them in more sophisticated ways so as to arrive at ideas of particular natural substances or artifacts. But it claims that such ideas are still necessary for experience in that we need them if objects are to be perceptually presented to us not merely as colored and shaped, but also as being (say) dogs or houses. So even though unsynthesized intuitions are not indeterminate, they still do not amount to perceptual experience in the perfectly ordinary sense in which we experience dogs as dogs and houses as houses. But this defense does not, it seems to me, avoid the worry about triviality. For this "ordinary" sense of perceptual experience is not the experience of the empiricists, which is restricted to the perception of things as having simple properties like colors and shapes. Kant's empiricist opponent can thus insist that on Kant's view, so construed, understanding is not a condition of experience proper, but rather a condition on making judgments on the basis of experience. My perceptual experience of this object as a dog, on the empiricist view, is in fact a composite formed from my experience of this particular arrangement of colored patches (or of this colored and shaped thing), and my judgment, based on that experience, that there is a dog present to me. So this construal ends up amounting to the straightforward view on which understanding is required not for experience proper (that is, in the empiricist sense), but only "experience" in the sense of empirical judgment. ${ }^{21}$ Moreover it is not clear what warrant there is in Kant's text for supposing that the "blindness" of unsynthesized intuition is meant to exclude the possibility of its representing things as, say, dogs or houses, while allowing that they can represent them as, say, green or square. For the rationale for the "blindness" claim is at least in part that intuitions, being singular, cannot represent things as having general features. And qualities like greenness or squarenessor even such finer-grained qualities as being of some particular shade of green or having the dimensions of a square of some particular size-are no less general than the property of being a dog or a house.

It might be proposed in response that the shapes and colors with which unsynthesized intuitions acquaint us are not qualities common to a multiplicity of things, but rather what are sometimes called "abstract particulars" or "tropes," that is, singular instances of universal properties. This proposal might be the basis of a second line of defense on which intuition presents us not, say, with this green color or this cubical shape as such, but rather with the green color or cubical shape of this green cube, regarded as distinct from the green color or cubical shape of any other green cube, even one which is indistinguishable from the first. This view of the 
content of intuition is proposed by Houston Smit, who relates it to the notion of an "intuitive mark" which Kant invokes at R2286 (16:299-300) (see Smit 2000, 254). ${ }^{22}$ What intuition presents us with, on this view, is "singular instances of the predicates through which we determine ... things in experiencing them" (ibid., 255). And this might seem to address the difficulty, in that it seems to accommodate the "blindness" of unsynthesized intuitions by denying that they present us with general features, while still allowing them a kind of determinacy which could give them a role in prescribing rules for synthesis. But the problem with this line of defense is that it is not clear how my acquaintance with a singular instance of the shade of green belonging to this green cube could indicate to me how the intuition which presents that instance is to to be combined with other intuitions presenting different instances of the same shade. For me to grasp that the intuition is to be combined with other intuitions according to some determinate rule corresponding to the shade of green, and hence that the cube is to be represented (in common with other identically colored objects) as having that shade of green, it would seem that my intuition must represent the singular instance of the shade of green as an instance of that shade of green. In other words, it is hard to see how intuiting a "singular instance of a property" (ibid.) could determine a rule according to which the intuition is to be synthesized, unless the intuition acquaints me not only with the singular instance of the property, but with a general feature that that singular instance has in common with other singular instances of the same property, namely, that of being an instance of that property. And if we suppose that, then we might as well be supposing that intuition presents us with universal properties after all: a supposition which brings us back to the first line of defense.

A third way of defending the approach might be to suggest that, while the unsynthesized manifold cannot acquaint us with qualities, it can nonetheless present its intuitions as standing to one another in relations of resemblance. Understanding can thus impose rules of synthesis that are suggested to it by the ways in which the elements of the manifold are similar to, and different from, one another. ${ }^{23}$ But here we have to be careful to avoid a potential ambiguity in the appeal to resemblance to explain how the manifold can play a role in determining rules of synthesis. If all that is intended is that one element of the sensory manifold in fact resembles another, then it is left open whether or not, in receiving the sensory manifold, we are aware of the resemblance. It could be, for example, that unsynthesized intuitions resemble one another in various respects without the resemblance itself registering in consciousness. (To make this thought more concrete, we might imagine resemblances of this kind being empirically detectable from a third-person standpoint: a sentient being, such as an animal, might respond behaviorally in one predictable way to green items or to cubes, and in another way to blue items or to spheres; and we might infer from that that the sensory impressions caused by any one of the green cubes were phenomenologically more similar to those caused by the other green cubes than to those caused by the blue spheres. But this would not imply that the animal was itself aware of its sensory impressions as resembling one 
another in these ways. One impression would be phenomenologically like another, and hence result in similar behavior, without the animal's representing the resemblance itself.) In that case the sensory manifold could not, as the approach under discussion seems to require, convey to understanding the rules for its synthesis. We can indeed make sense of the idea that the sensory manifold would in fact come to be synthesized in one way rather than another, namely in a way corresponding to the resemblances among its elements, but not of the idea that it would determine rules saying how it ought to be synthesized. If, however, we understand the appeal to resemblance as suggesting that the intuitions not only resemble one another in various ways, but are presented as standing in relations of resemblance, then we once again face a conflict with their supposed blindness. A manifold whose elements are represented as standing in relations of similarity and difference to one another no more counts as "blind" than a manifold whose elements are represented as colored or shaped. ${ }^{24}$

A fourth, and more indirect, line of defense might challenge my suggestion that the sensory manifold cannot determine that it ought to be synthesized in accordance with, say, the concepts green and cube, without thereby representing its object as green or as a cube. Objects come to be represented as having features, it might be objected, only insofar as the guidance supplied by the manifold of sensory intuition is supplemented by the understanding's application of the pure concepts to that manifold. I can thus represent something as a green cube only insofar as I also represent it—thanks to the contribution of understanding - as a substance endowed with qualities and standing in causal relations to other substances. On the version of the nuanced approach suggested by this line of defense, the "blindness" of unsynthesized intuitions results from the fact that they cannot represent their objects as determined according to the categories. It does not exclude the possibility of their contributing to a representation of objects as having determinate features by, so to speak, "filling in" what is needed to represent an object as a cube shaped rather than a spherical (or sphubical) substance, or as having the quality of greenness rather than blueness (or grueness). Unsynthesized intuitions do not then, on this view, present themselves or anything else as green or cube shaped; but they do have features such that, when they come to be synthesized under the direction of the understanding in accordance with the pure concepts of the understanding, they will come to be synthesized more specifically according to the concepts green and cube. ${ }^{25}$

But this line of defense is, it seems to me, illegitimate. For it attempts to defend the coherence of Kant's claim that experience involves understanding by appealing to a point which I take to depend on that claim-namely, that we need the categories in order to represent what is given to us in perception as having determinate features such as color and shape. On my understanding of the structure of Kant's overall view in the Critique, his claim that we need the categories in order to have perceptual experience-in particular experience which acquaints us with features like color and shape-depends on, rather than warranting, the more general assumption 
that perceptual experience involves the activity of understanding. This is an assumption that needs to be made plausible, or at least coherent, if Kant is to be able to argue more specifically that experience must be subject to the pure concepts by which all activity of the understanding is constrained. We need already to have made sense of the idea that perceptual experience requires understanding if we are to be able to go on to claim that, say, we cannot represent something as a green cube without representing it as a substance endowed with qualities; so we cannot appeal to that claim as a way of defending the coherence of the initial idea. To put the point more concretely: Kant's empiricist opponent might well simply insist against this line of defense that, insofar as the unconceptualized manifold determines whether an object is to be represented as a substance endowed with the quality of being green, or as a substance endowed with the quality of being blue, then it is, eo ipso representing what is given to us as green or as blue. On the empiricist position — which is, after all, quite plausible on the face of it—sensibility alone can acquaint us with the shapes and colors of things, and there is no need to suppose that this presupposes a priori representations of the things as substances, or as having qualities, or as standing in causal relations. So the envisaged reply simply begs the question against the empiricist. According to the empiricist, the contribution of sensibility as conceived on this model just is that of representing what is given as determinately shaped or colored, so that there is no distinction to be made between the allegedly "blind" intuitions playing their guiding role, and the determinate sense data which figure in the empiricist's own model of perception.

It might be asked at this point whether the blindness of unsynthesized intuition could be preserved by rejecting the assumption that it must play a normative, rather than a merely causal, role in determining how the manifold is synthesized. Perhaps - and we might consider this as a fifth possible line of defense- the unsynthesized manifold does not convey or indicate to the understanding how it ought to be synthesized, but instead merely triggers the application of this or that rule in the understanding's repertoire. When my vision is affected by a green cube, for example, the resulting intuitions are causally responsible for my imagination's following the green rather than the blue rule, and the cube rather than the sphere rule. But they carry no indication that these rules are appropriate; rather, they simply bring it about that my imagination engages in the formation of a green cube image rather than a blue sphere image.

The problem with this proposal, though, is that in ascribing a merely causal role to unsynthesized intuitions, it prevents us from doing justice to the idea that these intuitions comprise the content of experience, or, in Kant's terms, its matter. The role of these intuitions in our example is exhausted by their triggering the formation of an image with the intentional content green cube. But this means that the intuitions no more enter into that content than does any other element in the causal chain leading up to the formation of that image, for example the stimulation of receptor cells in the retina. The relation between the intuitions and the content 
of the perceptual experience they engender is purely external: the content of the experience does not reflect anything about the intrinsic character of those intuitions, but only the causal role which they happen to play in our psychology. The problem can also be put by noting that, at least on the line of defense as I have spelled it out so far, intuitions play no role in determining which rules the understanding has in its repertoire. Intuitions determine whether the rule which is triggered is green or blue, or sphere or cube, but that the available rules are green and cube rather than grue or sphube would seem to be a matter uniquely of how things are with the understanding. So the ascription of a merely causal role to intuitionat least one where its role is to activate this or that rule of understanding-in effect undermines the distinction between pure and empirical concepts. As in the earlier formulation of the problem, it prevents intuitions from playing the kind of content-determining role needed to do justice to Kant's idea that they comprise the matter of experience. The inevitable conclusion, then, would seem to be that understanding alone is responsible for the content of experience-for the fact, say, that being affected by a green cube engenders in us a green-cube rather than a gruesphube experience-whereas intuition is left to determine only which content is entertained on which particular occasion.

The solution, it might be proposed, is not to abandon the suggestion that unsynthesized intuitions play a causal rather than a normative role in the constitution of experience, but rather to pursue it in a more thoroughgoing way. Instead of supposing that intuitions trigger a process by which imagination is guided by normative rules prescribed by understanding, why not deny that the imagination's synthetic activity is normatively guided at all, and instead take synthesis itself to be a purely causal, rather than an intrinsically rule-directed, process? On this more radical proposal, which I will consider as a sixth and last defense of the nuanced approach, a green cube's affecting my senses brings about-as on the versions of the approach we have so far been considering - an imaginative process through which I come to form the image of a green cube. But, in contrast to the versions so far considered, this process is not carried out under the guidance of the concepts green or cube. To the extent that the "drawing" analogy still applies, the drawing is not carried out with an antecedent idea in mind of what one intends to depict; rather, it is as though one moves the pencil automatically, carried along by a sequence of blind impulses, and can recognize only afterward, by examining the result, what it is that one has come to depict. Synthesis on this proposal, while not guided by rules, could still be viewed as a law-governed process by which intuitions come to be combined or associated in orderly patterns. We could fill the proposal out by supposing, for example, that the intuitions that I have on seeing a green cube regularly bring to mind memory traces of the intuitions that I have had on other occasions of seeing green things and cubes, and that this leads, on any given occasion of seeing a green cube, to my anticipating a specific set of further intuitions associated with those other occasions. I thus come to form an image incorporating 
elements from previous occasions as well as the present one, so that, for example, I come to represent the cube as having six faces even though on the present occasion only three of the faces were visible to me, or as such as to look green in normal light even though, on the present occasion, I am seeing it in yellow light. ${ }^{26}$ But the fact that the previous intuitions which I recall are intuitions of a kind typically caused by green things and cubes, as opposed, say, to intuitions of a kind typically caused by blue things and spheres, is not a result of my present intuitions having somehow clued me in that green and cube are the appropriate rules to follow and hence that these are the intuitions which I ought to recall. More generally, the procedure by which I recall previous intuitions-which is to say the "synthesis of reproduction" which Kant takes to be central to the synthesis of the manifold-does not presuppose any antecedent grasp of rules at all, whether indicated by my intuition or originating in the understanding. Rather, my reproducing the particular intuitions that I do, and hence my forming the image of a green cube rather than, say, the grue-like image that might be formed if I recalled to mind some quite different set of intuitions, is due to the operation of purely natural laws; and I arrive at the concepts green and cube only when I subsequently reflect on my activity of synthesis with a view to understanding how it operates. As Patricia Kitcher puts it in defense of this kind of view: "rules govern syntheses only as the law of gravity governs the movements of the planets" $(1990,83)$. As she sees it, we become aware of these rules only when we adopt the perspective of theorists: "it is only when trying to explain cognition that we must be cognizant of rules of synthesis" (ibid., 84).

But this attempt at a more thoroughgoing naturalization of synthesis faces a problem which is, in a sense, the mirror image of that which I raised for the previous, less radical, proposal. The previous proposal ascribed too extensive a role to the understanding, in that it made the understanding responsible, apparently, for the entire content of experience. The present proposal, by contrast, seems to allow understanding no role at all in the constitution of experience: understanding is required only for the possibility of reflection on how our experience is possible. Once it is allowed that the synthesis can proceed automatically, without the subject's needing to appreciate that there are rules governing her synthesis or that she ought to reproduce this, rather than some other, set of previous intuitions, then there no longer seems to be any need for understanding to direct the processes by which we come to have experience, as opposed to its being required for the codification and explanation of those processes. To put the point another way, the proposal equates synthesis with a version-if perhaps a more psychologically sophisticated version-of Hume's association of ideas. And as Hume makes clear, there is nothing about the working of the human mind according to principles of association which distinguishes it from the minds of animals. So in effect, this view deprives experience of the spontaneity which Kant ascribes to human beings as opposed to animals. There is nothing left of the idea that experience is a "kind of cognition which requires understanding" (Bxvii). 
III.

I distinguished, in the previous two sections, between two approaches to the interpretation of Kant's view that experience requires understanding. On the "straightforward" approach, the activity of understanding in the constitution of experience is simply that of judgment: what Kant means by "experience" in this context is empirical judgments or knowledge, rather than the sensory data on which empirical judgments are based. On the "nuanced" approach, the activity of understanding in experience is not judgment but rather a kind of proto-judgmental activity of directing, that is prescribing rules for, imagination's synthesis of the manifold of sensible intuition. The nuanced approach promises to avoid a worry about triviality that threatened the straightforward view, but I argued that it faces a difficulty of its own. If it is not to collapse into the straightforward approach, then unsynthesized sensible intuition must be "blind" in a way that distinguishes it from the sensory ideas or impressions of the empiricists; that is, it must not acquaint us with general features or qualities of the objects with which it presents us. But if it has the required "blindness," then we cannot explain how it is capable of contributing to the content of experience.

At this point I want to consider a third approach which appears on the face of it to avoid both the worry about triviality and the difficulty I raised for the nuanced approach. This approach is developed by McDowell in the context of his treatment of a general philosophical problem, a treatment which he presents as derived from Kant's account of experience. The problem, which we can label as that of how empirical content is possible, ${ }^{27}$ or simply the problem of empirical content, is the central theme of his Mind and World (1994, 1996): it is the problem of how thought, judgment, or belief can be "answerable to the empirical world" (1996, xii) or how empirical judgments and empirical thinking can "bearing on ... reality" $(1994,5)$. The problem arises because of a difficulty in making sense of the relation between sense impressions, or the "world's impacts on our senses" on the one hand, and our exercises of thought—in particular, our beliefs and judgments—on the other. If our beliefs are to have "the sort of bearing on reality which empirical content amounts to" (ibid., 14), then they must be not merely causally, but also rationally constrained by sense impressions: sense impressions must be capable of serving as evidence for, and hence justifying, our beliefs. But if sense impressions are conceived of in the traditional way as prior to, and independent of, our capacity for thought, then they cannot play this rational or evidential role. For only something with conceptual content, and thus presupposing some kind of involvement of our conceptual capacities, can serve as a reason or justification for belief. The problem leads to what we can think of as a trilemma among three positions, each of them unsatisfactory. ${ }^{28}$ If we insist that nonconceptual sense impressions can provide rational constraint on beliefs, then we succumb to what Sellars called the "myth" of the Given. If instead we conceive of the relation between sense impressions and beliefs as merely causal, 
then we are committed either to coherentism or to "bald naturalism." On a coherentist view the content of any one of our beliefs is determined exclusively by its relation to our other beliefs, since if sense impressions do not stand in rational relation to beliefs, then they cannot determine their content. This view, McDowell thinks, is ultimately self-defeating: it prevents us from so much as making sense of the notion of a belief at all. Bald naturalism, on the other hand, allows us to make sense of the idea that the relation between beliefs and sense impressions is purely causal, but only by denying that there is anything sui generis about beliefs or other exercises of thought, or about the relations of rational justification which hold between them. It denies, in other words, that there is anything distinctive about thinking, and about the rational constraints to which thinking is apparently subject, which demands anything other than the kind of explanation offered in the natural sciences.

The solution to this problem, according to McDowell, is to reject the traditional view of sense impressions as independent of our capacity for thought. ${ }^{29}$ We must instead think of sense impressions as already possessed of conceptual content (1994, 9-10); only in this way can we make sense of them as standing in a justificatory or evidential relation to beliefs, and hence as endowing them with empirical content. The interest of Kant's view, for McDowell, is that, properly interpreted, it offers precisely this solution. McDowell sums up the solution, and the corresponding interpretation of Kant, as follows: "the way to stop oscillating [between coherentism and the Myth of the Given] is to conceive empirical knowledge as a co-operation of sensibility and understanding, as Kant does. To avoid making it unintelligible how the deliverances of sensibility can stand in grounding relations to paradigmatic exercises of the understanding such as judgments and beliefs, we must conceive this cooperation in a quite particular way: we must insist that the understanding is already inextricably implicated in the deliverances of sensibility themselves. Experiences are impressions made by the world on our senses, products of receptivity; but those impressions themselves already have conceptual content" (ibid., 46). When McDowell endorses one "quite particular way" of conceiving the cooperation of sensibility and understanding, or of receptivity and spontaneity, he is in effect ruling out the straightforward approach to the issue of how understanding, for Kant, is implicated in experience. When Kant says that understanding is required for experience, he is saying not just that it is required for empirical knowledge or judgment-Beck's " $\mathrm{K}$ experience"-but for sense impressions themselves; that is, for experience in a sense continuous with the sensory ideas and impressions of the empiricist tradition. And this way of reading Kant is important to McDowell not because it vindicates Kant's project of showing the applicability of the categories to objects given in experience, as in the line of argument I developed in section I, but rather because it is only on this reading that Kant is able to account satisfactorily for the empirical content of judgment and, more generally, of thought. To expand briefly on this point: the traditional empiricist picture on which sense impressions provide data for judgment is, as McDowell sees it, a version of the Myth of the Given. To adopt the straight- 
forward approach would be to assimilate Kant's view to this traditional picture, on which sensible impressions, which do not require understanding, serve as data for exercises of understanding through which empirical judgments are made. But if we instead approach Kant on the assumption that it is sensible impressions, and not just the empirical judgments that are supposedly based on them, which require understanding, then not only do we avoid this assimilation, but we are able to find in Kant the solution to the problem of empirical content.

I said that McDowell implicitly rejects the straightforward interpretation of Kant; does he, then, adopt the approach which I referred to as "nuanced"? His approach is like the nuanced approach in that it distinguishes the role of understanding within experience from its role in the formation of judgments. But in contrast to the nuanced approach, McDowell denies that the former role can be spelled out in terms of operations on a preconceptual manifold of intuition, for example by saying that understanding either synthesizes, or prescribes rules for the synthesis of, such a manifold: conceptual capacities are not "exercised on an extra-conceptual deliverance of receptivity," but rather "drawn on in receptivity" $(1994,9)$. The only sensible impressions in McDowell's account are those which are already endowed with conceptual content and which stand in grounding relations to belief; those sensible impressions cannot in turn be seen as arising from the exercise of the understanding on sensible impressions at some more fundamentally receptive level. There is, in other words, no "sheer receptivity": as McDowell puts it in a passage I quoted above, "the understanding is already inextricably implicated in the deliverances of sensibility themselves" (ibid., 46). Because of this, the issue which we found so problematic in the previous section, that of how "blind" intuitions can determine the rules by which they are to be synthesized, simply does not arise.

McDowell develops this aspect of his interpretation, in his (1998) Woodbridge Lectures, through a criticism of Sellars's claim, in Science and Metaphysics, that nonconceptual intuition for Kant must "guide" the conceptual activity involved in perceptual experience. According to Sellars, Kant's metaphor of productive imagination's "taking up" the manifold of outer sense implies "that the manifold is an independent factor which has a strong voice in the outcome" of this activity (1968, 16). But for McDowell the idea of nonconceptual intuition guiding conceptual activity, or having a "voice" in its outcome, represents, ironically, a lapse into the Myth of the Given criticized elsewhere by Sellars himself. A satisfactory interpretation of Kant can allow "guidance" only from what is already conceptual, or conceptually determined: that is, either sensible impressions as McDowell conceives them, or the conceptually determined objects that are revealed to us in those sensible impressions $(1998,467)$. The rationale for this aspect of the interpretation can be captured in more general terms by noting that, if McDowell were to allow that understanding either operates on, or is guided by, "sheer receptivity," then the problem of empirical content, having been solved at the level of judgment, would arise again at the level of experience. We would need to ask how, if at all, the manifold of sheer receptivity can determine the content of the sensible impressions in which 
understanding is already implicated, and we would face a parallel trio of unattractive answers corresponding respectively to the Myth of the Given, coherentism and bald naturalism. ${ }^{30}$ The only way to avoid the problem is, as McDowell puts it in Mind and World, to "disallow the question what conceptual capacities are exercised on in experience" $(1994,39)$. And indeed, according to McDowell, we should not think of understanding, in its role within experience, as so much as "exercised" at all; that way of speaking, he says, "would suit an activity, whereas experience is passive" (ibid., 10). Conceptual capacities within experience are not exercised but "drawn into operation" (ibid., 46) or "actualized" (1998, 439-40).

How, then, is understanding implicated in experience, if not through an activity of synthesizing preconceptual representations? As I understand McDowell's answer, understanding plays a role in experience simply in virtue of the fact that the contents of experience are conceptual; that is, that they are the same contents which figure in judgments. "In experience one takes in, for instance sees, that things are thus and so. That is the sort of thing one can also, for instance, judge" $(1994,9)$. The experience which I typically have when my senses are affected by, say, a green cube, is an experience of seeing that there is a green cube in front of me, or that this cube is green. This is an experience which I can have only if I am also capable of judging that there is a green cube in front of me, or that the cube is green; and because of that we can describe the experience as "drawing on" my capacity to make such judgments. McDowell develops this point, in the Woodbridge Lectures, in terms of the Sellarsian idea-with which McDowell is in agreement-of experiences as "containing" claims. The paradigmatic actualization of our conceptual capacities, according to McDowell, is in the form of judgments; for example, the judgment that there is a green cube in front of one. Here two distinct conceptual capacities, corresponding respectively to the concepts green and cube, ${ }^{31}$ are actualized with a "specific mode of togetherness" $(1998,439)$ whose specificity we can capture by noting that it is not present in the judgment that there is a green sphere and a blue cube in front of one. But these same conceptual capacities can be actualized, with the same mode of togetherness, in the perceptual experience one has when one sees that-as opposed to judging that - there is a green cube in front of one. And in this case their actualization is not "free" and "responsible" as it is in judgment (ibid., 439) but rather "involuntary" (ibid., 440). The judgment and the corresponding perceptual experience thus both have the same conceptual content, but differ in that in the one case the content is freely and responsibly endorsed, whereas in the other case we are, as he puts it in Mind and World, "saddled with content" (1994, 10). "One's conceptual capacities have already been brought into play, in the content's being available to one, before one has any choice in the matter" (ibid.).

McDowell's references here to the voluntariness and choice supposedly involved in judgment might seem problematic in a Kantian context, where the spontaneity associated with understanding and theoretical reason is, at least on the face of it, quite different from the practical freedom associated with the will. But his point can be captured less controversially in terms of a more general, and not necessarily will- 
dependent, notion of the assent or commitment involved in judging. I can see that there is a green cube in front of me, according to McDowell, without assenting to, or endorsing, the claim that there is a green cube in front of me. This can happen in a case where there is a green cube in front of me, and where the presence of the green cube also leads me to have a visual appearance as of a green cube in front of me, but where I withhold assent from the claim that there is a green cube in front of me because I falsely believe that the lighting conditions are abnormal or that I am the victim of a hallucination. In this case I am likely to judge that there is a green cube in front of me only if I come to be disabused of my false belief about the context in which I am having the experience, so that I no longer have a reason not to endorse the content of the experience. "That things are thus and so is the content of [an] experience ... it becomes the content of a judgment if the subject decides to take the experience at face value" $(1994,26)$. What distinguishes experience from perceptual judgment, and thus more specifically what secures the receptivity of experience in spite of its involving conceptual capacities, is that in experience there is no assent to, or endorsement of, the conceptual contents which figure in experience, whereas a judgment based on experience does involve such endorsement: "a judgment of experience ... endorses the conceptual content, or some of it, that is already possessed by the experience on which it is grounded" (ibid., 48-49). Because of this we can think of the experience as passive, as a matter of its being impressed on us that things are thus and so, rather than of our actively judging that they are thus and so. If there is indeed a green cube in front of me, and it appears to me in the normal way that there is a green cube in front of me, then the fact of there being a green cube in front of me is simply presented to me, in a way which requires no act of commitment on my part.

I am sympathetic to McDowell's denial that experience involves guidance from an unconceptualized sensory manifold. But I disagree with his construal both of the receptive aspect of experience- that is, of what it is about experience which distinguishes it from judgment—and of its spontaneous aspect - that is, what it is that experience has in common with judgment. I want to bring out this disagreement by raising two complementary objections which bear respectively on these two features of his view. The first, which I have developed elsewhere and so will describe only briefly here, is that if experiences do not carry with them commitment or assent to the claims figuring in their contents, then they cannot serve as rational grounds for judgments. This objection draws on the intuition expressed in Davidson's well-known remark that "nothing can count as a reason for holding a belief except another belief" (1986, 310). McDowell assumes that Davidson's point could be recast by saying that "nothing can count as a reason for belief except something that is already in the space of concepts" $(1994,140)$, but in fact Davidson wants to make the stronger point that, to be a reason, a psychological state must involve assent or commitment. The mere entertaining of a conceptual content is not enough to supply me with reasons for endorsing either that content, or any other content which is inferentially related to it. The sight of the full moon might, 
on some occasion, lead me to entertain the unendorsed thought that the moon is made of cheese, but this does not mean that I am justified either in believing that the moon is made of cheese, or in believing that it is edible. Now there is, of course, a difference between merely having a thought come to mind, and being, as McDowell puts it, "saddled with" a conceptual content in perception. But it is not clear that the difference is relevant to the question of whether I have a reason for belief. If, as in our earlier example, I am presented with a green cube but fail to believe that it is a green cube because I falsely take myself to be under an illusion, then it is not clear that I do have a reason to believe that a green cube is present to me. Thus, at least on the face of it, the supposedly unendorsed character of the contents of perceptual experience would seem to rule out the kind of rational relation between experience and judgment to which both McDowell himself, and Kant, are committed. ${ }^{32}$

The second objection can be introduced by asking how it is, on McDowell's reading of Kant, that we come to acquire the conceptual capacities which are paradigmatically exercised in judgment but also drawn on passively in experience, and in particular those capacities corresponding to empirical concepts like green and cube. On at least some versions of the nuanced view discussed in the previous section, concepts are acquired insofar as preconceptual intuitions indicate to understanding the rules according to which they are to be synthesized. Either we can think of this as a matter of intuition's directly putting us in possession of concepts - which is how we must think of it if we identify rules with concepts-or we can think of the rules as merely protoconceptual, and suppose that concepts proper are arrived at through reflection on the experience we arrive at through synthesizing intuitions in accordance with these rules. In either case we are committed to an abstractionist view of concept acquisition, although in the second case the abstractionism is of a more subtle kind. McDowell is clearly committed, on Kant's behalf, to rejecting both alternatives, and, in the Woodbridge Lectures, he explicitly takes issue with Sellars's ascription, to Kant, of the second kind of abstractionism (1998, 454 and 454 n.3; see also 1994, 7). Concepts, for Sellars's Kant, are abstractively derived from "protoconceptual" intuitions: intuitions which have already been synthesized but whose content is not itself conceptual. On McDowell's reading, there is "no opening" $(1998,462)$ into this kind of abstractionist account because intuitions are already straightforwardly conceptual: "Visual intuitions of objects simply are seeings that ..., looked at as it were from a different angle" (ibid.). A visual intuition of a green cube is not the kind of representation from which the concepts green or cube can be acquired by abstraction, since it is already a case of seeing that there is a green cube in front of one, and hence already draws on the conceptual capacities corresponding to green and cube. But then it looks, at least on the face of it, as though McDowell owes us an alternative account of how these concepts are acquired. McDowell's view blocks an abstractionist account of concept acquisition by assuming that experience presupposes conceptual capacities, which a fortiori cannot be acquired from experience, but this apparently still leaves us with the question of how we come to possess them. 
The closest that McDowell comes to offering an account of empirical concept acquisition is, as far as I know, in the remarks he offers in Mind and World about acquiring a "second nature." His model for the idea of second nature is the acquisition of Aristotelian practical wisdom, in which we come to appreciate, or become responsive to, the rational demands of ethics. But he sees this Aristotelian idea as "a particular case of a general phenomenon: initiation into conceptual capacities, which include responsiveness to other rational demands besides those of ethics" $(1994,84)$. Acquiring a second nature is a matter of "having one's eyes opened to reasons at large" (ibid.) where these include reasons for belief as well as for action. Our second nature makes us aware of the structure of what McDowell, following Sellars, calls "the space of reasons" (ibid., 88). Although McDowell is not at all explicit about how this applies to conceptual capacities like those corresponding to green and cube, it is plausible to suppose that acquiring or being "initiated" into such capacities is of a piece with "having one's eyes opened to reasons" because, in acquiring a concept like green, one becomes aware of actual and possible rational connections among one's beliefs, or among one's beliefs and experiences. To acquire the concept green is, in part, to come to appreciate that if one sees or believes that something is green, then one has a reason for believing that it is colored, or that it is visible. It is also to come to appreciate, say, that something can be rationally believed to be green, even if it is not seen to be green, if one believes that one would see it to be green under normal lighting conditions.

Now according to McDowell, Kant "lacks a pregnant notion of second nature" (1994, 110; see also ibid., 97), so that an account of this kind is not available to him. But the notion of second nature is just what Kant needs, again according to McDowell, if his insight about the relation of spontaneity and receptivity in experience is not to "show up ... in a distorted form" (ibid., 98). So we can still think of what McDowell says about the acquisition of second nature as belonging to his interpretation of Kant, in the sense that he takes it to express what a Kantian view of experience must be committed to if it is to be philosophically satisfactory. How, then, on this interpretation, are empirical conceptual capacities acquired? McDowell characterizes the acquisition of second nature in terms of the German philosophical notion of Bildung; while this term connotes ideas of culture or becoming cultivated, ${ }^{33}$ he emphasizes that Bildung is a natural process, an "element in the normal coming to maturity of the kind of animals we are" (ibid., 88). He also says that, in our conception of Bildung, we should "give pride of place to the learning of language" (ibid., 125). For "in being initiated into a language, a human being is introduced into something that already embodies putatively rational linkages between concepts, putatively constitutive of the layout of the space of reasons, before she comes on the scene" (ibid.). And he expands on this by noting that natural language "serves as a repository of tradition, a store of historically accumulated wisdom about what is a reason for what" (ibid., 126). We might provisionally take McDowell's point to be, at least in part, that rational connections are embodied in the structure of language, so that when a child comes to acquire linguistic capacities she both 
comes to have a sense of these connections and comes into possession of the corresponding conceptual capacities. The fact that believing something to be green is a reason for believing it to be colored or to be visible, is something of which we can become aware simply by mastering the use of the terms "green," "colored," and "visible." And something similar goes for the rational connections that are grasped in appreciating the ways in which something can look green without being green (say, because of abnormal lighting conditions), or be green without looking green (say, because it is in the dark). Learning to use words like "green," "color," and "daylight" amounts, then, to becoming aware of such rational connections, and, equivalently, to acquiring mastery of the corresponding concepts.

I emphasize that this understanding of McDowell is provisional because it is not clear to what extent he intends the notion of Bildung, or more specifically of initiation into language, to play a genuinely explanatory role in accounting for the acquisition of conceptual capacities, as opposed to being just another way of characterizing what goes on when we acquire such capacities. McDowell at one point characterizes the space of reasons as "the framework within which meaning" —of which linguistic meaning is presumably the paradigm - "comes into view" (1994, 88). This suggests that learning a language, which is a matter of becoming responsive to the meanings of terms, is not a means by which we come to appreciate the structure of the space of reasons, but rather something which is either simply of a piece with initiation into the space of reasons, or indeed something which is made possible through our grasp of reasons. However at other points he suggests that the appeal to language learning is intended to help us understand how we come to acquire responsiveness to reasons and, correspondingly, conceptual capacities. For example, he introduces the idea that language learning is central to Bildung by saying that it allows us to "take ... in our stride" a "transformation" which otherwise "risks looking mysterious"; namely, that of a human being from a "mere animal" to a thinker and intentional agent (ibid., 125). We can, he says "make sense of" a human being's "matur[ing] into being at home in the space of reasons ... by noting that the language into which a human being is first initiated stands over against her as a prior embodiment of mindedness" (ibid.).

But if we take at face value the suggestion that the appeal to language learning is supposed to help us explain how we come to acquire conceptual capacities, then it is hard not to avoid questions, in turn, about how we come to learn a first language. To come quickly to the question which arises most naturally in the context of McDowell's view of experience: how can an individual learn the use of an observational term like "green"—or, for that matter, "cube," whose acquisition is also typically keyed to observation-if she is not already in some sense capable of seeing the things around her as green or as cubes, or at least as having some distinctive features in common which serve to legitimate the application of this or that term? How does she know to project her own use of "green" from the initial set of samples associated with her parents' or teachers' utterances of "green" to other green things - as opposed, say, to things that are grue-if she is not somehow aware of 
these other green things as having something in common with the samples which makes the utterance of "green," again, appropriate? For McDowell, at least if we understand his view as one in which language learning is explanatory of concept acquisition, our capacity to experience something as green or as a cube is made possible by our mastery of a language which has terms corresponding to "green" and "cube"; it cannot be presupposed as a condition of our acquiring such mastery. But that raises a question, on the face of it, about how we are capable of acquiring a language in which observationally keyed terms play a central role.

It might be replied that learning the appropriate use of terms like "green" and "cube" is just something which happens in the course of natural human development. And indeed this reply is at least suggested in McDowell's characterization of Bildung as a normal part of human maturation, and more specifically as the development of innate capacities: "[o] ur Bildung actualizes some of the potentialities we are born with; we do not have to suppose that it introduces a non-animal ingredient into our constitution" $(1994,88)$. We might suppose, then, that the tendency to project our responses to green things as we do, as opposed to "going on" in a gruelike way, is simply one of our innate potentialities. We are born with other such potentialities, say for the projection of terms like "herbaceous" or "painterly," but these come to be actualized only if our Bildung includes initiation into wine tasting and art appreciation; and in a culture which had no use for colors, the potentiality reflected in our projection of "green" would remain unrealized. If this is how language learning is understood, then asking why a child comes to project "green" in the typical way rather than in a grue-like way is like asking why she grows hair instead of leaves. She does not need any reason to project "green" from the initial set of samples to new instances of green objects, and nor, in particular does she do so because she sees the new instances as green. Even though it is a cultural fact about her that it is "green" which she comes to use in this way rather than "grün" or "vert," and, more generally, that she comes to use color words at all, the fact that her pattern of use takes the form that it does is simply a reflection of her biological endowment, and, more specifically, of what Quine (1969) calls her "innate standard of similarity" or "innate spacing of qualities." The explanation of that fact will be no different in principle from the explanation we might give for why a pigeon who has been rewarded for pecking at an initial sample of green objects goes on subsequently to peck at objects that are green rather than grue. ${ }^{34}$

But this cannot be the whole story, for McDowell, about how language learning is possible. For if it were, then there would be no room to raise questions about whether a given pattern of projection, or "way of going on," is or is not appropriate. And this would conflict with McDowell's view that it is essential to the very idea of a conceptual capacity that concepts-even our most observational conceptsare open to being "reshaped" or "refashioned" on the basis of reflection $(1994,13)$, and that consequently we are under a standing obligation to "ensur[e] that our empirical concepts ... pass muster" (ibid., 40). To say that the patterns in which we use our terms are no more than an expression of our innate potentialities is, in 
effect, to rule out the possibility that our concepts are open to "reflective criticism": that, for example, reflection can "disclose weaknesses in inherited ways of thinking" which in turn can "dictate the formation of new concepts" (ibid., 81). Even though it leaves room, on the face of it, for spontaneity in the application of a concept in a judgment-deciding in a particular case whether something is green may require reflection on other properties it possesses, on the lighting conditions in which it is seen, on the way other people respond to it, and so forth-the concept itself is something which is fixed by our biological nature, something with respect to which we are passive. But on the "demanding" interpretation of concepts to which McDowell says he is committed (ibid., 47), we must think of ourselves as engaged in active reflection, not just with respect to the use of our concepts in judgments but with respect to concepts themselves.

This, however, is not yet an objection to McDowell's account, since he can accommodate the idea that our concepts are open to criticism by supposing that one concept can be evaluated in the light of other concepts, or in the light of experiences conceived - as of course McDowell thinks they must be-in conceptual terms. Our conceptual capacities belong to "a network that rationally governs comprehension-seeking responses to the impacts of the world on sensibility" (1994, 12) and elements of the network can be criticized in relation both to one another and to the "impacts of the world," themselves conceptually structured, which we are seeking to comprehend. Correspondingly, we can think of the language learning in which the acquisition of conceptual capacities consists as involving an appreciation of the way in which the use of one word can be a basis for criticizing and reshaping the use of others, in the light of experiences which are made possible through one's developing mastery of the language itself. To take a very crude and artificial example: suppose that, due to some quirk in the language learning process, a child-who otherwise uses color words more or less correctly-habitually applies "green" only to green objects that are opaque, refraining from applying any color term to objects which are green and translucent. We might imagine her at some point reflecting on her use of other color words, say her use of "red" as applying to translucent as well as opaque objects, and as a result coming to correct her usage of "green" so that it applies also to translucent objects. As a result of this reflection, a translucent green thing now strikes her, in a way it did not before, as colored; and because of that she is now prepared to call it "green." On this view, language learning would not simply be a mere actualization of innate potentialities, but also a rational, or at least protorational process. The child, then, would not simply find herself with the concept green, but would have acquired it in a way which was at least sensitive to the possibility of its being shaped by reflection on its relation to other concepts and to experiences with conceptual content.

I have been suggesting so far that a satisfactory account of language learning, for McDowell, must combine both of the elements we have been discussing: language learning must involve the actualization of innate potentialities to develop one rather than another pattern of linguistic use, but it must also incorporate the pos- 
sibility of correcting and revising any one of these pattern of linguistic use in the light of others. How can these two elements be integrated into a single account? We might begin by supposing that they correspond to two distinct stages in language learning, one more primitive and the other more sophisticated. At the initial stage, it might be supposed, language learning consists in the unreflective acquisition of habits of response. The child becomes accustomed to responding to green things with "green" in much the same way that a pigeon might be trained to peck at green patches, and the fact that her pattern of response is green-rather than grue-like is, as with the pigeon, entirely a matter of her innate tendencies to respond one way or another to a given kind of conditioning, that is, her "innate spacing of qualities." But once her repertoire of habits has become sufficiently rich, the supposition continues, she finds herself in a position to adopt a reflective attitude to her ways of responding, and to criticize one way of responding in terms of others. This corresponds to the second, more sophisticated level of language learning, which has no analog in the case of the pigeon. However, while this way of combining the two elements might seem to have a certain amount of psychological plausibility, it is unsatisfactory as it stands, for it leaves us with the mystery of how the transition between the two stages is accomplished. In order to think of the child as criticizing one pattern of response in terms of others, we must already think of these patterns of responses as to some extent expressive of a grasp of concepts. But at the initial stage of language learning, as described on this model, the child's habits of response do not, by McDowell's lights, count as conceptual at all.

We might do better, then, to think of the two elements as corresponding, not to different stages in the child's development, but rather to an idealized distinction between two kinds of linguistic response that a child makes in the course of language learning. On this model of language learning the child is capable from the very beginning of appreciating, albeit in an inchoate way, the appropriateness of some of her linguistic responses in the light of others. We can thus think of her patterns of "going on" in her use of a word as shaped simultaneously by her innate propensities to respond one way or another to conditioning and her appreciation of one kind of response as a reason, or proto-reason, for other kinds of response. But each of these elements plays a more or less significant role depending on how closely the child's linguistic responses are tied to observation. If a child is learning color words by being shown objects of an unfamiliar kind, or familiar objects whose features give no clue to what color they are (say, blocks and balls as opposed to apples and bananas), then her patterns of linguistic response will be almost entirely an expression of her similarity space. Her responding with "green" to a given object will not be mediated by her appreciation of the appropriateness of any other linguistic response: correspondingly, to the extent that her learning of that response plays a role in her acquiring of the concept green, her acquisition of that concept will be independent of her appreciating its rational relations to other concepts. By contrast, she initially learns to use a word like "fruit" by coming to correlate its use with that of other words like "apple" or "banana." This kind of learning 
does involve the appreciation of the appropriateness of one pattern of word use in the light of another, and hence allows room for evaluation and revision of concepts. The child can consider whether "fruit" should apply, say, to avocados: and here she will have to draw, not just on her immediate inclinations to respond in this way or that to a given avocado, but on other concepts she applies to avocados and to fruits more generally (avocados are not served as dessert, but they do grow on trees; they are not sweet, but nor are lemons, which do count as fruit; they are not kept in the fruit bowl, but nor are raspberries; and so on).

The account which I have just sketched seems to me to offer a plausible spellingout of McDowell's hints about the acquisition of conceptual capacities. But if it is McDowell's view, then - and here I come, finally, to the objection I have been working toward - then it cannot do the work McDowell needs it to do if he is to provide a satisfactory answer to the problem of empirical content. For it commits him to a view of concepts which is problematic in just the same way that coherentism is problematic, and which we might indeed describe as a form of coherentism, although at the level of concepts rather than at the level of the judgments and beliefs which presuppose them. If the only normative constraints on word use that the child is capable of appreciating are constraints which apply in relation to other aspects of word use, then the content of the corresponding concepts is determined exclusively by their relation to other concepts. ${ }^{35}$ The biological fact that a child's dispositions to project linguistic responses are green-rather than grue-like plays a merely causal role in determining the child's patterns of word use, and is thus, at least on the assumptions which motivate McDowell's own criticisms of coherentism, irrelevant to the content of the corresponding concepts. So, as with the coherentism which McDowell criticizes, we are faced with the specter of "frictionless spinning in a void" $(1994,11)$. The child's pattern of responses to as yet unconceptualized green things plays no role in determining which concept she is on her way to acquiring: all that counts for fixing the content of her concepts are those responses which are mediated by her appreciation of the applicability of other concepts. So if we grant that the concept which the child acquires, in learning to use "green," is indeed the concept green rather than the concept grue, this can only be because it is tied into a network of other concepts which includes red rather than gred, color rather than schmolor, and so on. But then it is not clear how we can make sense of the idea that the concept is an empirical concept, or in other words that the child's acquisition of green rather than grue reflects something about how her receptivity is affected, as opposed to being a product of pure spontaneity. And, again following the logic of McDowell's own critique of coherentism, this in turn calls into question whether we can count her as having concepts at all. ${ }^{36}$

The objection I have just sketched can also be formulated as a direct challenge to McDowell's solution to the problem of empirical content as he himself articulates it, that is, as a problem about the empirical content of thoughts and judgments. That solution turns on the idea that we are, in experience, passively "saddled with" conceptual contents $(1994,10)$. McDowell makes out this idea by contrasting 
the content of experiences with that of judgments and beliefs. In experience "one's conceptual capacities have already been brought into play, in the content's being available to one, before one has any choice in the matter. The content is not something one has put together oneself, as when one decides what to say about something" (ibid.). When I see that there is a green cube in front of me, the content of my experience is not up to me: I cannot for example decide to have it visually appear to me that there is, instead, a blue sphere in front of me. By contrast, I can in a sense decide to judge that there is a blue sphere in front of me, as I might do if I am told that I am in unusual viewing circumstances where blue things look green and spheres look like cubes. In that case, even though I believe that there is a blue sphere in front of me, it will still appear to me that there is a green cube in front of me, and assuming that I have been misinformed, and the viewing circumstances are in fact normal, I will, according to McDowell, see that there is a green cube in front of me.

But once we consider the question of how our conceptual capacities are acquired, and with it the question of why we come to have the concepts we do rather than their grue-like variants, then we have to recognize a sense in which the content of my perceptual experience is not, after all, something I am "saddled with," but is, instead, something which is "up to me." For it is always in principle open to me to revise my system of concepts in such a way that I come to reject the concepts green and cube and replace them with variant concepts like grue or sphube. And that means that it is in principle open to me, in the very same physical circumstances in which I now find myself (that is, with a green cube in front of me, and under normal viewing conditions) to have a visual experience with a different content, namely, one in which I see that there is a grue sphube in front of me. Of course, if I were to carry out a revision of this radical kind independently of changes in the linguistic practice of those around me, then I would be, in effect, severing myself from the language community into which I had been initiated, and that is no doubt a practical impossibility. But we could imagine changes of a less radical kind, bearing on less immediately observational concepts, yet with a similar effect. When, to draw on a textbook example from the history of science, Lavoisier rejected the concept of phlogiston, he also brought about changes in the content of some of his visual experiences: in circumstances where it would previously have appeared to him visually that a piece of metal was dephlogisticated, he now saw that it was oxidized. And, to return to the original example, although I might not on my own be capable of bringing about the kind of conceptual change envisaged, we could suppose that it is carried out by the language community as a whole, so that even if we cannot make out a sense in which my seeing that there is a green cube in front of me is up to $m e$, we can still make out a sense in which it is up to $u s^{37}$

Now McDowell would, I think, reject this entire line of objection on the grounds that it assumes what he calls a "sideways-on picture" of our system of concepts, or of how our thought bears on the world $(1994,35)$. In particular, he might say, we cannot intelligibly raise the question of how a concept like green is acquired 
except within a context in which the possibility of concepts is already taken for granted. We can indeed make sense of concept acquisition in terms of learning a language, but only if the idea of learning a language is itself understood in conceptual terms, as presupposing meaning. The child learns to project "green" to green things rather than to grue things, and hence comes to acquire the concept green rather than grue, because she is learning English, and in English "green" means green rather than grue. But there can be no explanation of how the child acquires the concept green in terms of linguistic behavior described in terms that do not presuppose meaning, say, as the realization of a set of responsive dispositions. Relatedly, McDowell might reject the threat of a coherentism at the level of concepts on the grounds that we simply cannot ask how our system of concepts as a whole comes to have empirical content. The question of empirical content arises only for thoughts and judgments, and we can address it only by appealing to experiences understood as already conceptual. My thought that this is a green cube has empirical content in virtue of the fact that, endowed as I am with the concepts green and cube, I can have experiences in which something's being a green cube is revealed to me. But it makes no sense to then go on to ask how, in turn, the concepts green and cube can have empirical content, since that question presupposes a picture on which the conceptual sphere is, as McDowell puts it, enclosed by an "outer boundary" $(1994,34) .^{38}$ And this rejection of the possibility of a "sideways on" view of concepts is, of course, not just a part of McDowell's own view, but also a part of what he thinks Kant needs in order to preserve his insight about the conceptual character of experience.

But to the extent that McDowell disallows, on Kant's behalf, the question of how the concepts which figure in experience are themselves possible, his own account fails to provide a genuine alternative to Sellars's reading of Kant. For when Sellars, in Science and Metaphysics, introduces the idea of "guidance" by preconceptual intuitions it is as a way of addressing just that question, or at least a question very closely related to it: the question of how our perceptual responses to the world come to be, not merely the kind of discriminatory responses which he describes as characteristic of flatworms and white rats, but conceptual responses. There is, he says, a "genuine question" to be asked: "Why does the perceiver conceptually represent a red (blue, etc.) rectangular (circular, etc.) object in the presence of an object having these qualities" $(1968,18)$ ? Granted that there is a green cube in the vicinity, how can we explain how the perceiver comes to represent it as a green cube, as opposed, say, to merely representing it in a way which differs systematically from the way in which she represents blue spheres? Sellars makes clear that this is a question about the possibility of the acquisition of concepts, and he considers the possibility that we could dispense with the appeal to guidance by nonconceptual intuitions by appealing, instead, to language learning. We might try to answer the question by saying that "one is taught by one's linguistic peers, who already have the relevant concepts and propensities, to play the color-shape language game, and, by so doing, acquire these concepts and propensities" (ibid., 18-19). However, accord- 
ing to Sellars, this explanation "supplements, but does not replace the original suggestion" that we are guided by preconceptual intuitions (ibid., 19). This is because "the ability to teach a child the color-shape language-game seems to imply the existence of cues which systematically correspond" (ibid.) to color and shape properties. In other words, a child cannot acquire the relevant conceptual capacities, even with training in the use of language, unless there is something given to her in sensation which she can recognize as correlating with the use of the words she is learning, and which thus serves as a cue or guide to the appropriate use of those words. ${ }^{39}$

McDowell, I think, fails to appreciate the force of the question which Sellars is asking. He quotes Sellars's formulation of the question and glosses it, in my view correctly, as that of how "sensory relatedness to the environment takes the form of conceptual episodes" (1998, 444). But he goes on to characterize Sellars as concerned with how to "vindicate the objective purport of conceptual occurrences" (ibid., 445) and with how "thought... [can] be intelligibly of objective reality" (ibid., 467). These characterizations also fit a question different from that asked by Sellars: not that of how a subject comes to acquire the concepts green and cube, but rather how a subject already endowed with the concepts green and cube can deploy them, or draw on them, in such a way as to enjoy a conceptual episode that is intentionally directed toward an actual green cube there in the world independently of her. Now when McDowell suggests that, instead of appealing to guidance by preconceptual intuitions, we can appeal to guidance by "objects themselves ... becoming immediately present ... to sensory consciousness" (ibid., 467) it is, I think, this second question which he is answering, and not the question which was asked by Sellars. Our conceptual occurrences can relate intentionally to objects that are independent of us because objects can reveal themselves to us in experience; but they can do so only insofar as we possess the corresponding conceptual capacities. In McDowell's picturesque formulation, drawing on the image of "voice" introduced by Sellars, the object "speaks" to me: "'See me as I am,' it (so to speak) says to one; 'namely as characterized by these properties' - and it displays them" (ibid., 468). But as McDowell also points out, objects "speak to us ... only because we have learned a human language," or, "less fancifully put, objects come into view for us only in actualizations of conceptual capacities that are ours" (ibid., 470). The green cube can present itself to us as green and as a cube only because we have learned a language which contains words like "green" and "cube," and, in so doing, acquired the corresponding conceptual capacities. That means that we cannot appeal to the guidance it offers in order to explain how we can learn that language, and thus acquire those conceptual capacities, in the first place. And, as we have seen, it is precisely this possibility which Sellars's own account is intended to explain.

I have challenged McDowell's rejection of sideways-on views of concepts by saying that it prevents him from engaging fully with the concerns motivating Sellars's interpretation of Kant; there are also grounds for arguing that McDowell fails, for similar reasons, to engage fully with Kant's own concerns. This last argument can be pressed in connection with McDowell's interpretation of Kant's notion 
of synthesis, an interpretation which is not worked out in detail but which underlies his discussion of the Metaphysical Deduction (see in particular 1998, 457-62). In the Metaphysical Deduction, Kant contrasts the "mere synthesis of various representations in an intuition" (A79/B105) with the combination of representations in a judgment, and this contrast is usually taken to imply that the elements combined in "mere synthesis" are nonconeptual, in contrast to the conceptual elements which are combined in a judgment proper. But McDowell is committed, by the same considerations which commit him to rejecting sideways-on views of concepts, to holding that the elements which are combined in synthesis are always themselves conceptual. So he proposes an alternative interpretation of "mere synthesis" on which the relevant contrast is not between two different kinds of elements, nonconceptual and conceptual, but rather between a merely passive combination of conceptual elements - as when we find ourselves confronted in experience with the presence of a green cube-and the kind of active combination of conceptual elements involved in judging that a green cube is present. The point of Kant's reference to "mere synthesis," he says, "is simply that it does not take cognitive work for objects to come into view for us. Mere synthesis just happens; it is not our doing, unlike making judgments, deciding what to think about something. This is quite consistent with holding that objects come into view for us in actualizations of capacities that are fully conceptual, capacities whose paradigmatic mode of actualization is in ... judging" $(1998,462)$. We "engage in" this or that act of synthesis, then, insofar as we find ourselves entertaining, in perception, this or that combination of conceptual contents. And what Kant would call different "acts" of synthesis with respect to the same given elements differ insofar as the same conceptual contents are perceptually entertained in different combinations: for example, when one perceives that there is a green cube and a blue sphere in front of one, as opposed to perceiving that there is a green sphere and a blue cube in front of one.

But while the combination of conceptual contents is indeed an aspect of what Kant understands by synthesis, McDowell's reading fails to accommodate Kant's conception of synthesis as operating also at a more fundamental level, in making possible the representation of a presented item as, say, green or cube shaped in the first place. This conception is implicit in the same passages which I cited in section II (and, not coincidentally, in the further passages which I reported Sellars as citing) to show why one might be tempted to understand perceptual synthesis on the model of drawing a picture. ${ }^{40}$ And other passages, not directly bearing on perception, suggest that synthesis is required if conceptual content is so much as to be entertained by us, regardless of whether this requires a combination of conceptual contents. Kant says, for example, that "we cannot think of a line without drawing [ziehen] it in thought, we cannot think of a circle without describing it" (B154). The synthesis to which Kant alludes in speaking of "drawing" or "describing" is required, not for the possibility of entertaining different conceptual contents in this or that combination (say, that here is a green circle) but rather for the very possibility of entertaining a conceptual content like line or circle at all. 
As I noted earlier, I think that McDowell is right to reject the view, held both by Sellars and by most proponents of the nuanced approach, that Kant's account must appeal to the idea of guidance by an unconceptualized sensory manifold. But the two objections raised in this section suggest that McDowell's own alternative is unsatisfactory. Recall that the problem we have been considering throughout is that of how experience, for Kant, can require understanding while still counting as a means through which objects are given to us, or, to put it formulaically, how experience can involve both spontaneity and receptivity. McDowell's solution is to identify the spontaneous aspect of experience with its conceptual character, and its receptivity with the absence of assent or endorsement. Having an experience does not require the exercise of judgment, in the sense of commitment to a claim, and this is what ensures its receptive character. But it nonetheless draws on the conceptual capacities which are paradigmatically exercised in the making of judgments, and this gives it its aspect of spontaneity. The two objections I have raised challenge, respectively, these two aspects of McDowell's solution. If experience does not involve judgment in the sense of assent, then it cannot constitute grounds for belief, as it must if it is to provide a basis for empirical judgments more generally. But conversely, if experience draws on conceptual capacities which are antecedently possessed, then we are faced with an intractable problem about the content of the corresponding concepts.

A natural next step, if one is persuaded by one or other of the two objections I have raised, would be to insist against McDowell that Kant cannot dispense with an appeal to guidance from nonconceptual intuition. This would be to return to some version of the nuanced view discussed in the previous section, and, at least if we wanted to read Kant's view as philosophically coherent, it would require us to reject the claim that the nonconceptual Given is a "myth." But I want to suggest a different approach, which endorses McDowell's denial of guidance by a nonconceptual Given, but which radically reworks his positive view through, so to speak, rearranging its basic elements. McDowell, I want to suggest, is right to try to reconcile the receptive and spontaneous aspects of experience by invoking, on the one hand, the notion of judgment in the sense of commitment or endorsement, and, on the other hand, the notion of a state's drawing on antecedently possessed conceptual capacities. But in identifying the receptive aspect of experience with the absence of judgment, and its spontaneous aspect with the presence of concepts, he gets things, in my view, precisely the wrong way round. The account I want to propose, and which I will sketch very briefly in the next section, adopts what is, in effect, the reverse strategy. On my account, in contrast to McDowell's, experience does involve judgment in the sense of commitment or assent, and it is for that reason that it counts as spontaneous. Conversely, however, and again in contrast to McDowell's view, it does not presuppose the antecedent possession of conceptual capacities, and that is why it qualifies as receptive. 
IV.

My own proposal for addressing the problem can best be introduced against the background of the radically naturalistic account described at the end of section II. I introduced this account as a variant of the nuanced approach, since, in common with other versions of that approach, it distinguishes the activity required for the constitution of experience from that required for judgment proper. But, as I pointed out, it is unlike the other versions considered in that it rejects the idea that the synthesis by which experience is constituted is guided by rules. Intuitions are "reproduced" in regular patterns so as to bring about determinate perceptual images, but they are reproduced in those patterns due to the operation of natural laws, rather than to the subject's appreciation that they ought to be reproduced in this or that way. This means that we need not face the difficulty of explaining how allegedly "blind" intuitions can afford the subject a grasp of the rules according to which those intuitions are to be synthesized. It is not for experience itself, but only for theorizing about it, that we need to grasp the "rules," that is to say the natural laws, which govern the synthesis through which experience is made possible. Howeverand this was the reason I gave for rejecting it-this naturalistic account fails to do justice to Kant's view that understanding is required not just for reflection on experience, but for experience itself. The processes by which experience is constituted are no different from those which take place in animals, so that although we might speak of a psychological activity of synthesis, that so-called activity lacks the genine spontaneity associated with understanding.

But I now want to propose a way of modifying this naturalistic account so as to introduce the missing element of spontaneity. The proposal is that we give the account of synthesis what I have, elsewhere, called a "normative twist" $(2006,49)$ : we understand the subject's activity of synthesis, in spite of its character as a naturally determined process, as involving her awareness that she is synthesizing as she ought. More specifically, according to the proposed account, on each occasion that the subject calls to mind, or reproduces, some previous intuition, she does so with the sense that what she is doing is normatively appropriate to her present circumstances, that is, that it is appropriate given the intuitions which she presently has. And she has this sense of appropriateness even though her reproducing the intuition in question is not guided by any appreciation of what she ought to be doing, nor, in particular, by the recognition of any features of her past or present intuitions which make it appropriate for her, under these circumstances, to reproduce this one rather than that. Her consciousness of normativity in what she is doing is "primitive" in that it does not presuppose the antecedent grasp of a specific rule: she is aware of her act of reproduction as being as it ought to be, but where its being as it ought to be does not depend on its satisfying an antecedently specified constraint. The primitive character of this consciousness, and likewise of the normativity of which she is conscious, can be captured by describing her sense of normativity in 
demonstrative terms. In synthesizing as she does, she takes it that this is what she ought to be doing under these circumstances, but in a way which does not depend on her being able to characterize what she is doing or the nature of the circumstances which require it, nor, a fortiori, on her grasp of a general rule prescribing which intuitions ought to be reproduced on which occasions. ${ }^{41}$

This can be illustrated by going back to the example mentioned briefly at the end of section II in connection with the naturalistic view. Suppose an ordinary adult is presented with a green cube which she sees only from one angle and in a yellowish light. Assuming that she is familiar with cubes and with the perception of colored things under a range of different lighting conditions, she will come to form an image which presents the cube as a green cube and which thus incorporates elements for which there are, on the present occasion, no directly corresponding sense impressions. Her image will in a sense include the faces of the cube which are not directly in her field of vision, and, assuming that she is not deceived by the unusual lighting conditions it will also represent the cube as having the color it would seem to have under normal lighting conditions. ${ }^{42}$ This happens, on the naturalistic view, not because she is guided by the concept of a green cube as on the "drawing" model as I initially presented it, but rather due to a natural process along the lines of Hume's association of ideas. The impression made on her by the green cube in the present circumstances leads her to call to mind impressions made on her by cubes and by green things that she has seen previously, and under better conditions of observation. She thus naturally comes to incorporate into her image elements derived from those earlier occasions of observation (when, say, she had the opportunity to look at the cube from a variety of angles, or to handle it; or when she saw one and the same green thing in a range of different lighting conditions). And if the defender of the naturalistic view is asked why the subject recalls impressions associated, precisely, with previously perceived green things, rather than grue or bleen things, the answer (at least as I am conceiving that view) will be that this is purely a matter of her innate natural dispositions, perhaps in combination with training which makes her sensitive to color differences. The account of why her patterns of recall take a green-rather than a grue-like form will not differ in principle from that which might be offered to explain why a pigeon which has been trained to peck at an initial sample of green things goes on to peck at further green things rather than at further grue things.

Now so far the account I am proposing coincides with the naturalistic view. In particular, it offers the same answer to the question of why the subject reproduces her representations according to a green-rather than a grue-like pattern. But on my proposed account there is something fundamentally different about the character of the process of reproduction, namely that, in spite of being naturally determined, it is also informed by the sense of primitive normativity which I have just described. It is not merely the case that impressions associated with previous perceptions of green things come to the subject's mind, it is also the case that they come to her mind with a sense of their appropriateness to the present circumstances of perception. This 
distinguishes her imaginative reproduction from that of, say, the pigeon, which might also be supposed to recall sense impressions associated with previous perceptions of green things, in particular impressions of the reward it received when it pecked at them, but which cannot plausibly be supposed to take its imaginative response, or the pecking through which that response is manifested, to be appropriate to its present circumstances. And it also distinguishes her activity from other forms of imaginative reproduction which take place in human beings, but which are not involved in the constitution of perceptual experience, for example, when someone is reminded of a long-forgotten friend by the smell of the perfume she used to wear or the sight of a house she once lived in. In this last kind of case, even when the subject recognizes why the memory of her friend has come to mind, she still takes the association to be an idiosyncratic one, not one which might be regarded as in any sense required, or called for, by the perceptual circumstances. By contrast, on the view I am proposing, the kind of imaginative association which yields perceptual experience involves the subject's implicit awareness that she is responding imaginatively as she, and anyone else under the circumstances, ought to respond. She is implicitly aware, for example, that if she were instead to recall impressions associated with her previous perception of blue things, thus synthesizing in a grue-like pattern, she would be perceiving the present object wrongly.

I shall not attempt here to justify this proposed account, either as an interpretation of Kant's account of the synthesis involved in perception, or as a plausible view in its own right. What I do want at least to suggest, though — and this might stand as a partial justification for adopting it as a reading of Kant-is that the account offers a way of making sense of Kant's claim that experience requires understanding, while still accommodating its character as receptive. Experience requires understanding, on this account, because insofar as the subject's imaginative synthesis involves the awareness of its own appropriateness with respect to the circumstances, it carries with it the kind of commitment or endorsement that is characteristic of judging. In reproducing a previous impression with the sense that this is what is called for or required by her present circumstances, she is in effect making a normative demand: that she, and anyone else in her circumstances, ought to synthesize in just this way. And because of this, I want to suggest, her synthesis counts as an act of judgment, or equivalently, as an exercise of spontaneity and hence of understanding. To adopt McDowell's terms for characterizing the spontaneity of judgment, she takes responsibility for her synthesis: even though the way she synthesizes is not in fact "up to her," she nonetheless commits herself to it and thus in a sense makes it her own.

When I introduced the nuanced approach in section II, I described it as one on which - in contrast to the straightforward approach — the understanding's role in experience differs from that of judging in the traditional sense. I took, as the paradigm for such an approach, a view on which the understanding guides or directs the synthesis of the sensible manifold by prescribing rules which the imagination follows, and I noted that the activity of understanding on this kind of view could 
be described as a kind of judging, albeit intuitive rather than discursive. The account which I am proposing has in common with the nuanced approach that the role it ascribes to understanding in experience is different from that played by understanding in the formation of discursive judgments. It denies that understanding's role in experience is that of combining concepts, or at any rate concepts which the subject already possesses. But my account departs from the nuanced approach, at least in the paradigmatic form just mentioned, in the way it construes the role of understanding in experience. For it dispenses with the idea that understanding prescribes rules by which synthesis is guided, and more generally with the idea that understanding plays any directive role at all. The role of understanding is exhausted by our appreciation, in synthesizing, that we are synthesizing as we ought. While we are indeed aware, in synthesizing, of how we ought to synthesize (in the form of the demonstrative awareness that in these circumstances we ought to synthesize like this) this appreciation does not play any role in determining how the manifold is in fact synthesized by us. So, just as on the purely naturalistic account, our synthesis is not guided by our appreciation of how we ought to synthesize, nor by our grasp of rules governing our synthesis. It is for this reason that we can continue to think of it as passive or receptive even while allowing that it involves understanding: that we synthesize in accordance with one pattern rather than another is a function solely of how we are affected and of our natural dispositions to associate the corresponding sense impressions.

This point of contrast between the approach I am proposing, and the nuanced approach in its paradigmatic form, helps us to see how my approach avoids the apparent dilemma faced by the nuanced approach with respect to the "blindness" of unsynthesized intuition. We saw that the nuanced approach has to interpret unsynthesized intuitions as different from, and more specifically as falling short of, sense data as understood by the empiricists. For otherwise it faces, with the straightforward view, the threat of triviality. If unsynthesized intuitions are not blind-if, like the sense data of the empiricists, they present us not only with individual things but also with determinate qualities like shapes and colors-then it would seem that it is these intuitions, rather than the product of their synthesis, which deserve the title of experience. And if that is so, then Kant has then shown that the categories are required for experience only in a contrived sense of "experience," corresponding not to perceptual experience in the empiricist sense, but rather to what the empiricists would have characterized as empirical judgment or knowledge. But, as we also saw, insistence on the blindness of unsynthesized intuitions seems on the other hand to prevent our ascribing to them any role in determining the content of the experience that results from their being synthesized. For if the intuitions cannot indicate to the understanding how they are to be synthesized-if, in Sellars's metaphor, they have no "voice" in the outcome of synthesis-then it would seem that the rules for synthesis must derive from the understanding alone. Intuitions are debarred from playing a guiding role in the constitution of experience: so it would seem that the only source of rules to guide the process of synthesis must be the understanding 
in isolation. Understanding prescribes rules for synthesis, but, it would seem, without benefit of any cues from sensibility about which rules are appropriate, either in general, or with respect to any manifold in particular.

The account which I am proposing grasps the first horn of the apparent dilemma. Unsynthesized intuitions play a causal, not a guiding, role in the constitution of experience: given our natural dispositions to associate representations one way rather than another, sense impressions of a kind typically elicited by a green cube will cause us to reproduce impressions elicited previously by green things and cubes, but they will not indicate to us that we ought to recall these impressions in preference to any others. There is thus no threat that having such impressions, prior to synthesis, amounts to our being aware of what is given to us as green, or as a cube. ${ }^{43}$ Such awareness is possible only if we actually call to mind impressions previously elicited by green things and cubes, with the sense that what we are doing is appropriate. But the denial that sense impressions guide our activity of synthesis does not yield the consequence that the rules of synthesis are determined by understanding alone. For what determines which rules govern our synthesis-whether it is governed in general by green- or grue-like roles, or whether on a particular occasion we ought to synthesize according to the rule green or according to the rule blue - is how we are in fact disposed to synthesize, which is a fact about what Kant would call our "sensible nature" rather than the faculty of understanding. That our synthesis counts as governed by normative rules überhaupt is a function of the awareness of normativity which it involves, and it is in virtue of this awareness of normativity that we can say that the understanding is involved in experience. But, at least when it is a question of empirical rather than pure concepts, the understanding does not determine that synthesis is governed by one rule in preference to any other: rather, it makes it the case that the natural regularities of association to which our imaginative reproduction in fact conforms can also be viewed as providing normative standards for, and hence as normatively governing, the activity of synthesis.

I now want to return briefly to the comparison with McDowell's view which I hinted at in the previous section. I indicated there that, while my interpretation of Kant agrees with McDowell's in holding that perceptual experience does not require guidance from preconceptual or unsynthesized intuition, it diverges from McDowell's in denying both that experience lacks the commitment or endorsement characteristic of judgment, and that it draws on antecedently possessed conceptual capacities. But it is important to note that I do not take the denial that experience depends on antecedently possessed concepts to imply that the content of experience is not conceptual at all. For in fact I believe that perceptual experience, as understood on the account I am proposing, should be counted as having conceptual rather than nonconceptual content. When the subject whose senses are affected by a green cube calls to mind impressions elicited by previously perceived green things and of cubes, and does so with the sense that she is responding appropriately to her circumstances, she is eo ipso perceiving what is given to her as green and as a cube: and, as I see it, this is just what it is for the concepts green and cube to figure in her 
experience. ${ }^{44}$ The normative claim implicit in her experience allows us, then, to think of her experience not only as an exercise of judgment, but also as having conceptual content. A subject with the same dispositions to associate her representations, but without the sense, in actualizing these dispositions, that she is doing as she ought, would merely be manifesting a capacity to respond differentially to green things and to cubes. But given her awareness of a normative dimension to what she is doing, she counts as applying the concepts green and cube to what is presented to her, even if she did not possess those concepts prior to the experience in question. ${ }^{45}$

I am thus in agreement with McDowell that, when a normal adult subject sees a green cube, her experience can be described as one in which she sees that there is a green cube in front of her. And I also agree with McDowell both that the content of this experience is something which she is, in effect, "saddled with," and that this is what allows us to say that her experience has a receptive character. But because I do not suppose that she has to possess the relevant concepts prior to having the experience, my account can do better justice than McDowell's to the receptivity of experience. A subject can be saddled with the conceptual content of her experiences only under the condition that she is saddled with the concepts which figure in those experiences, and we saw that on McDowell's view that condition does not appear to hold. Whereas on the view I am proposing, the subject is saddled not only with that particular propositional content on that particular occasion, but with the concepts themselves which figure in that content, since they are determined by her natural dispositions to associate representations one way rather than another. So there is a sense in which, on my account, the receptivity of experience is more thoroughgoing than on the view presented by McDowell.

But my account allows at the same time for a more demanding interpretation of the spontaneity involved in experience, and in particular of the idea that experience requires understanding construed as the capacity to judge. For, unlike McDowell, I do not take the receptivity of experience to rule out that, in having a perceptual experience, one commits oneself to, or endorses, the content of that very experience. On McDowell's view, as we saw, having an experience does not involve one's actualizing one's capacity to judge in the sense of actually judging, and this is so precisely because judging requires the kind of endorsement which McDowell thinks is incompatible with the receptivity of experience. So there is only an attenuated or indirect connection between what one does (or what takes place in one) when one has an experience, and what one does in judging: rather than employing one's capacity to judge, one draws on concepts which are paradigmatically employed in judging, but which are not being used to judge in this particular instance. On my reading, however, it is intrinsic to a subject's perceptual experience that she takes herself to be perceiving as she ought, so that her experience has built into it the kind of normative commitment characteristic of judgment. And it is this commitment, rather than dependence on concepts as such, which I take Kant to be signaling with his claim that experience "requires understanding." 46

I want to conclude by commenting briefly on what might seem to be a striking omission in my account of what it is for experience to require understanding: 
namely, that I have said nothing about the contribution of the categories to the constitution of experience. Surely, it might be protested, we cannot do justice to the role of understanding in experience without acknowledging that experience involves a priori connections among our sensible representations, and more specifically, that these a priori connections come about through understanding's application of the pure concepts to the sensible manifold. In characterizing the role of understanding in experience simply as the awareness of normativity in our synthesis, I seem to have left out of account what, to any reader of the Critique of Pure Reason, will seem like the most crucial contribution of understanding to experience, that is, that it allows us to conceive the objects of our experience as substances, endowed with qualities, standing in causal relations, and so on.

While there is much to be said about this issue, I will confine myself here to recalling a point which I made in the introduction and then again in section II, in response to the fourth line of defense which I proposed for the nuanced approach. Kant's project of showing that the pure concepts are conditions of the possibility of experience cannot succeed, as I see it, unless we can make sense of the idea that experience requires concepts, and thus the understanding, überhaupt. But it is just this idea whose coherence is challenged by what I have been calling the "problem of experience." The problem of experience is the problem of how we can conceive of experience as requiring any contribution of understanding at all-whether this contribution is realized in the form of pure concepts, in the form of empirical concepts, or in any other way-while still acknowledging its character as receptive. And that problem cannot be addressed by appealing to the role of the categories in experience, since if we cannot make sense of how experience can involve concepts überhaupt, then we cannot make sense of the role of the categories in experience either. Here it is important to bear in mind that Kant's concern in the Critique of Pure Reason is not the problem of experience, but rather the problem of how we can have substantive cognition a priori. So when he describes the categories as "conditions of the possibility of experience" he is not appealing to the categories as providing an answer to the problem of experience, but rather claiming the necessity of the categories for experience with a view to defending their objective validity and hence the validity of the a priori judgments in which they figure. However his claim, as I understand it, depends on a certain conception of experience which is problematic for reasons which have nothing to do with pure concepts as such, but rather with the very idea that experience can be conceptual or, more generally, that it can require understanding. It is that idea, in its most general form, which has been my concern in the present article.

\section{NOTES}

This paper expands on a talk given at a North American Kant Society meeting in April 2004; subsequent versions were presented at UCLA and to the philosophy discussion group of the Max Planck Institute 
for the History of Science in Berlin. I am grateful to Quassim Cassam for his insightful comments on the original presentation and to audiences and participants on all three occasions, including Tyler Burge, Katherine Dunlop, Barbara Herman, Pamela Hieronymi, Katharina Kaiser, Edwin McCann, Seana Shiffrin, Thomas Sturm, Udo Thiel, Bernhard Thöle, and Falk Wunderlich. For criticism, suggestions and discussion on other occasions, I am grateful to David Forman, Stefanie Grüne, Patricia Kitcher, Ulrich Schlösser, Sally Sedgwick, Houston Smit, Daniel Warren, and especially Eric Watkins, who commented very helpfully on the paper at several stages in its development. I would also like to acknowledge the American Council of Learned Societies and the Max Planck Institute for the History of Science for their support during work on this paper.

1. Of the commentators with whose work I am familiar, the two who come closest to engaging directly with the problem I have in mind are Wilfrid Sellars and, building on Sellars's work, John McDowell. For Sellars's approach, see his Science and Metaphysics (1968), especially chapter 1, and, in addition, his 1967, 1976, and 1978. McDowell's approach, which is presented in his Mind and World (1994) and his Woodbridge Lectures (1998), will be the focus of section III. A number of commentators have addressed the closely related difficulty of how "blind" intuitions of sensibility can constrain the activity of understanding in judgment; in addition to Sellars and McDowell, see for example Pippin (1982, especially chapter 2), Walker (1985), and, more recently, Manning (2006). I discuss this difficulty in what follows, especially section II, but in my view it is most helpfully treated as part of the broader problem I try to articulate here.

2. I follow the standard practice in quoting from Kant, using the A and B page numbering for the first Critique and volume and page number of the Akademie edition (1902-) for passages from other texts. Translations are my own, but I have consulted, and often followed, those of Kemp Smith (Kant 1929), of Pluhar (Kant 1996), and of Guyer and Wood (Kant 1998).

3. By "experience ... in the sense associated with the empiricist tradition," I have in mind primarily the simple sensory ideas of Locke and Berkeley, and to some extent Humean impressions. It is, of course, controversial how these sensory ideas and impressions are to be understood, and one might question both whether it is possible to isolate a single empiricist conception of "experience," and, if so, whether it is any less subject to worries about incoherence than I take Kant's to be. Nonetheless I will assume throughout that readers will recognize, both in the eighteenth-century empiricist tradition, and in more recent discussions of perception within epistemology, something corresponding to the distinction I am drawing here between experience on the one hand and judgment on the other, and I am hoping that the distinction has enough prima facie plausibility to serve as a backdrop for the worries I want to raise about Kant's view.

4. I will abbreviate this point in what follows as the "threat of triviality." Eric Watkins has suggested to me that, whether or not Kant can show that the pure concepts are required for perceptual experience in what I am calling the empiricist sense, it could still be a substantive achievement to show that empirical judgment requires the use of a priori functions of the understanding, and, more specifically, of the categories. So perhaps "triviality" is too strong a term. Still, it has to be conceded that Kant's conclusion, understood in the light of this approach, is considerably less significant than might be hoped.

5. Commentators who take the passage at face value include Beck (1978) and Hanna (2001, 199; 2004, 259-60). As Beck notes, both Norman Kemp Smith and H. J. Paton take the contrary view, although they differ in their accounts of the role that the passage plays in the text: Kemp Smith takes it to represent a remnant of pre-critical writing, whereas Paton holds that Kant was, for pedagogical reasons, raising a possibility he later intended to reject (Beck 1978, 39-40). Other commentators who take Kant ultimately to reject the possibility raised in the passage include Robert Paul Wolff (1963, 93-94 and 190) and Guyer and Wood (Kant 1998, 725 n.17).

6. Hanna challenges this standard reading of $\$ 26$ by appealing to a distinction between "forms of intuition" and "pure or formal intuitions" (2004, 277); it is only the latter, he says, which necessarily involve our conceptual capacities. It is not clear to me, though, how Hanna's reading succeeds in accounting for Kant's conclusion at $\$ 26$ that all perceptual synthesis is subject to the categories (see the paragraph following in the text).

7. The question of the division of labor between imagination and understanding is a difficult one; I discuss it in more detail in section II of "Lawfulness without a Law" (Ginsborg 1997). Some 
commentators have denied that the imaginative synthesis required for perception is to be ascribed to understanding; for example, Hanna distinguishes "a lower-level or sensory (receptive) spontaneity" associated with the activity of imagination in perception, and a "higher-level or conceptual (discursive) spontaneity" belonging to the understanding $(2001,37)$. But, as with the point mentioned in the previous note, it is hard to see how Hanna's view is to be reconciled with the passages from $\$ 26$ that I go on to quote in the text, and there is also something paradoxical about the idea of a spontaneity which is, itself, receptive.

8. I am adopting Longuenesse's version of this approach as my starting point because it suggests a useful prima facie distinction between the respective roles of imagination and understanding: understanding prescribes the rules and imagination follows them. This aspect of her view is of a piece with Strawson's suggestive characterization of imagination as the "lieutenant" of understanding $(1966,97)$. Another version is offered by Sellars, for whom the role of understanding in perceptual experience is that of making possible conceptual representations with a form like "this cube" which are not themselves judgments, but which are required for us to have representations like "this cube is a die," which are judgments (1968, 4-6; 1967, 636-38). In Science and Metaphysics, Sellars does not characterize understanding as offering rules for imagination, but rather identifies the two faculties: imagination "under the name 'productive imagination"” (i.e., in its role as making possible perceptual experience) just "is the understanding functioning in a special way" $(1968,4)$. But in "The Role of the Imagination in Kant's Theory of Experience" (1978), Sellars describes the productive imagination as a "blend of a capacity to form images in accordance with a recipe, and a capacity to conceive of objects in a way which supplies the relevant recipes" ( $\$ 31$, 238 , emphases omitted); this suggests a model on which imagination follows rules supplied by understanding, although both the rule-supplying role and the rule-following role are ascribed to productive imagination as a single faculty.

9. Sellars officially denies that synthesized intuitions count as judgments; in generating "intuitive representings of the 'this-cube' form" we generate, not judgments, but "the subject-terms of perceptual judgments; thus, for example "This cube is a piece of ice" (1967, 638). But he also speaks of the latter kind of representing as a "full-fledged judgment" (ibid.), suggesting that perceptual representings of the "this-cube" form are at least fledgling judgments, and he also proposes to simplify his treatment of Kant by abstracting from the distinction between intuitive representings and judgments (ibid.).

10. I offer some support for this reading of Locke and Berkeley in section II of my 2006. I also give reasons there for suggesting that Hume's view is quite different.

11. Something like this interpretation of the "blindness" of unconceptualized intuition is suggested in Hanna (2001). An unconceptualized intuition is a "bare sensory indicator" (47) of its object; my sensory field in such an intuition "manifestly includes an occupant, but yields no further determination of the discriminating characteristics of that occupant" (49); someone who intuits a red object "blindly" sees "an obscure this X now over there" but not yet "this red thing" (50); the so-called savage in the Jäsche Logic who lacks the concept house "sees a house but not as a house" (200). But it is not easy to square this interpretation with a weaker construal of "blindness" defended in some other passages in Hanna (2001) and also in Hanna (2004, see note 20).

12. Although Kant sometimes distinguishes concepts from the corresponding rules or schemata, I will treat concepts as identical with rules, as suggested by Kant's treatment of the concept of body at A106. I discuss the relation between concepts and rules of synthesis in section II of my "Lawfulness without a Law" (1997).

13. I here follow Pluhar's translation of verzeichnen. Two further passages cited by Sellars in support of the "drawing" model are B137-38, where Kant says that "to cognize something or other-e.g., a line-in space, I must draw [ziehen] it," and A102, where he describes the "synthesis of reproduction" in imagination as needed to "draw [ziehen] a line in thought" (see Sellars 1967, 643).

14. The drawing or image formation model, incorporating the idea that we come to see something as an $\mathrm{F}$ by forming an image of it in accordance with the rule or concept $\mathrm{F}$, is developed in Strawson 1970 and, in an especially detailed way, in Sellars 1978.

15. Longuenesse makes a similar point about the limitations of Kant's analogy between synthesis and mathematical construction $(1998,48)$.

16. As acknowleged, for example, in Paton's claim that "the concept 'house' is at work, even if uncon- 
sciously" in the synthesis by which we "[combine] a series of given appearances into the complex intuition of one individual house" (1936, vol. 1, 264). See also Hanna: "one must employ an empirical concept in order to overcome the indistinctness or blindness of a bare intuition" (2001, 49; Hanna's emphasis).

17. I give the second of these examples because some people have objected that Goodman's actual grue, with its reference to a specific time, is automatically excluded as a potential rule of synthesis by the status of time as one of the forms of sensibility. (For a more general version of this objection, see the next note.) I am not myself persuaded by the objection, but readers who are troubled by the time reference in Goodman's grue or by the reference to a particular spatiotemporally located individual in the first of my examples should understand my references to "gruelike" concepts as picking out examples like the second.

18. A number of people have suggested to me that Kant's various a priori constraints on experiencethe forms of intuition, the categories, and in particular the a priori principles of reason and reflective judgment-are sufficient to rule out grue-like and other nonstandard concepts. The thought behind this seems to be that any set of empirical causal laws governing objects in space and time and meeting Kant's requirements on systematicity would have to be framed in terms of concepts like ours, rather than their grue-like or disjunctive alternatives. But I do not see why, if human imagination consistently synthesized everything that was given to it in a grue-like way, we could not arrive at a system of experience no less successful than our own in meeting Kant's a priori requirements.

19. According to Walker 1985, this is in fact the view represented in the first edition of the Critique.

20. Hanna argues in his 2004 that the "blindness" of unconceptualized intuitions is compatible with their qualifying as a kind of cognition and as being objectively valid. Kant's claim that intuitions without concepts are blind is meant to maintain the interdependence of intuitions and concepts "only for the specific purpose of constituting objectively valid judgments" (2004, 257; see also 2001, 203). This means that the blindness of intuitions amounts simply to the fact that they do not, on their own, amount to or constitute judgments; for them to constitute judgments, they must be complemented by concepts. Moreover, he claims in a different but related context that experiences with nonconceptual cognitive content—-hence, presumably, "blind" intuitions—can stand in evidential or justificatory relations to belief or judgment. This is because "the intrinsic spatiotemporal structural phenomenal (in Kant-speak, "aesthetic") character of such experiences ... confers an optimal phenomenal articulation or lucidity upon their nonconceptual perceptual content, and thereby, just by virtue of this optimally articulated or lucid content, synthetically necessitates the perceiver's assertoric belief in a corresponding propositional content that is cognitively built right on top of that nonconceptual perceptual content" $(2004,264)$. This weak interpretation of the blindness of intuitions, which allows them an "optimally articulated" content standing in justificatory relations to belief, is of a piece with Hanna's apparent endorsement of the straightforward view: intuitions, it would seem, qualify as experience in the empiricist sense, and the understanding is required not for the possibility of experience as such, but only for making judgments on the basis of experience. But this way of understanding blindness seems to me to be incompatible with his other characterizations of "blind" intuitions as indeterminate indicators of space-occupancy (see note 11).

21. It might be replied that my experience of what is given as a dog incorporates, not a judgment on the basis of the given data, but rather an interpretation of that data. Relatedly, the work of synthesis might be seen as that of interpreting elements given in sensory intuition, rather than as on the model here under discussion, combining them. A view like this is at least hinted at in Prauss 1971 (see especially $\$ 3$ and \$7) and in Kitcher 1999 (see 431-34). But even if we allow the distinctionwhich seems to me to be unclear-between offering an interpretation of given data and making judgments based on the data, it is still hard to see how the appeal to interpretation can avoid the problems discussed in the text. An interpretation must be, at least to some extent, normatively constrained by the data which it interprets, and the question of how sensible data can constrain the interpretation while still counting as "blind" is no less difficult than the question of how the unsynthesized manifold of intuition can determine the rules according to which it is to be combined.

22. A related view has been suggested to me, in conversation, by Eric Watkins. 
23. This line of thought is at least hinted at in Longuenesse's remark that, for Kant, "universals" (that is, concepts) "represent resemblances lending themselves to 'rules of apprehension"” $(1998,120)$. Mark Okrent also appeals to the idea that we can be "acquainted with difference and similarity" or that we can "see similarities and differences" in a way which does not presuppose understanding $(2006,106)$.

24. Okrent aims to overcome this kind of difficulty by appeal to a "non-conceptual intuitive grasp" or "non-conceptual intuition" of similarity and difference $(2006,107)$; he allows that we do not have a good grasp on what this involves, but still thinks that its possibility is guaranteed by the fact that animals have it. However, it is not clear to me that we can say of animals that they grasp the similarities and differences among their representations, as opposed to merely that they have representations which in fact stand in relations of phenomenological similarity and difference. Moreover, it is also not clear to me whether the notion of a nonconceptual intuition of the similarities and differences among things is any less problematic than appeal to a nonconceptual intuition of, say, their colors and shapes: to grasp a similarity between things is to grasp a certain relation in which they stand to one another, but nonconceptual intuition, being singular, would seem no better able to provide a grasp of the relations between things than of their nonrelational properties or features. The point here is related to one made by Sellars at $\$ 29$ of "Empiricism and the Philosophy of Mind" $(1956,289)$.

25. This is one possible way of spelling out Sellars's view that while nonconceptual intuitions do not present us with, say, colors, they do have "characteristics which, without being colours, are sufficiently analogous to colour to enable [them] to play [a] guiding role" in conceptual representation $(1968,18)$. The thought seems to be that our coming to see objects as having determinate observable properties is the joint result of our having intuitions with characteristics analogous to these properties, and our synthesizing these intuitions in accordance with the pure concepts of the understanding $(1968,30)$.

26. This account of image formation draws on Strawson (1970) and Sellars (1978); I return to it in section IV (see note 42 ).

27. The label is drawn from McDowell (1996, xxi).

28. In speaking here of a "trilemma," I am simplifying McDowell's own conception of how the various positions are dialectically related: McDowell describes us as subject to an "oscillation" (1994, 9) between coherentism and the idea of the Given, and he introduces "bald naturalism" not as a competing position on the same level as coherentism and the appeal to the Given, but rather as an "opting out" of the area of philosophy in which the problem of empirical content arises (ibid., 67). The next note describes a related simplification.

29. My reference to a "solution" again simplifies McDowell's position: McDowell takes himself, not to be answering the question of how empirical content is possible, but rather to be "exorcising" the philosophical anxieties which it expresses. Like bald naturalism (see the previous note), the position developed by McDowell is intended not to provide a solution, but to show that there is no problem (1996, xx-xxi). There is, however, a broad sense in which McDowell's "exorcism" can be seen as proposing a solution, albeit to a higher-level problem: that of how we are to conceive of experience and its relation to judgment in such a way that the anxieties bundled into the "problem of empirical content" do not arise. For ease of exposition I shall continue to describe McDowell, and McDowell's Kant, as offering a solution to the problem of empirical content, although, strictly speaking, any solution they offer is to the higher-level problem rather than to the problem of empirical content proper.

30. The various defenses of the nuanced view which I described in the previous section correspond to versions of these three positions, transposed to the level of experience: the first four defenses appeal in various ways to the idea of the Given, the fifth represents a form of coherentism, and the sixth amounts to a "bald naturalist" position.

31. "Corresponding to the concept green" abbreviates the idea that it is the conceptual capacity which would be exercised both in judging that there is a green cube in front of one and in judging that there is a green pyramid in front of one $(1998,438)$.

32. This line of objection has been developed by Barry Stroud (2002). I develop it further in "Reasons for Belief" (2006c).

33. See Pippin $(2002,60)$. 
34. Consistently with his rejection of a "sideways-on" view of concepts (discussed later in this section), McDowell might object here that this is not what he means by "innate potentialities": the potentialities which Bildung actualizes, he might say, are not potentialities to use words in this or that pattern, where the pattern is described in a meaning-free way, but rather potentialities to use words with this or that meaning, say, the potentiality to use a word like "green" in such a way as to mean green. But this does not seem to fit with his claim that "human beings are ... born mere animals, and they are transformed into thinkers and intentional agents in the course of coming to maturity" (1994, 125); human beings would be born, on this view, not as mere animals but rather-in contrast to animals, at least as conceived by McDowell_-as potential thinkers.

35. Talk of the "content of concepts" might seem problematic; perhaps, as Colin McGinn argues (although in a somewhat different context comparing concepts with words of a language) a concept just is its content $(1984,146)$. But McDowell himself sometimes speaks of the "content" of concepts $(1994,19,33)$; and in any case the point can be rephrased to avoid the locution: we can say for example that it is only its relation to other concepts which makes a given concept the particular concept that it is.

36. The worry that McDowell's view represents a form of coherentism or (more or less equivalently) idealism is not new: it is raised, for example, by Michael Friedman (1996; see especially 442-44) and by Richard Manning (2006), and it is also considered by McDowell himself in both Mind and World, especially lecture II, and in the Woodbridge Lectures, especially 466-73. My version of the worry differs from those mentioned in that it focuses on the content of concepts, rather than on the contents of propositional items such as thoughts and judgments.

37. In his reply to a paper by Dennis McManus, McDowell emphasizes that we might find ourselves, after reflection, "stuck with" certain rational connections $(2000,334)$, and I take it that the same point would apply to concepts. So McDowell might say here that the concepts green and cube are concepts that we discover, on reflection, just cannot be given up or revised, at least barring radical changes in the environment (e.g., to cite his example at ibid., 333, human visual responsiveness to light no longer being keyed to wavelength). However, the sense in which we would find ourselves "stuck" with these concepts, would, I think, have to be the kind of sense McDowell goes on to illustrate with Luther's "I can do no other" (ibid., 334). Luther thought he had no choice but to stand where he stood; but this does not mean, as McDowell points out, that he thought that his action was not free. By the same token, if we find that we have no choice but to endorse the kinds of rational connections which commit us to a system of concepts including green but not grue, it still does not follow that these concepts are not "up to us"; and it is this last thought that provokes the worry about a form of coherentism.

38. In fact McDowell does at one point raise a question about what he calls the "empirical substance" of concepts (which, as the last sentence on page 33 of 1994 suggests, is equivalent to their "empirical content"; see also the equation of "content" and "substance" at 1994, 4). Specifically, he says that the sideways-on picture is incapable of depicting "anything genuinely recognizable as an understanding of a set of concepts with empirical substance," because the fact that "these supposed concepts could be bound up with impacts from the world only causally, not rationally ... leaves their status as concepts with empirical substance, potential determinants of the content of judgments that bear on the empirical world, a mystery" (ibid., 35). McDowell's thought here seems to be that concepts derive empirical content from the fact that they "determine the content of" judgments which, in turn, have empirical content in virtue of standing in rational relations to experience. Because the sideways-on view does not allow for rational relations between judgments and experience, it prevents us from making sense of judgments as having empirical content, and this in turn-so the thought goes-prevents us from making sense of concepts as having empirical content. But this explanation does not bear on the question about their empirical content which I have been raising, since it explains the empirical of concepts by appeal to experience construed as already presupposing conceptual capacities, whereas I have been asking how we are to make sense of the possession of conceptual capacities in a context where it is not already taken for granted that experience is conceptual.

39. David Forman makes the same point, also in connection with this passage, in his "Learning and the Necessity of Non-Conceptual Content in Sellars's 'Empiricism and the Philosophy of Mind"'(forthcoming). (He also argues that Sellars's view that sense impressions are needed for language learning does not originate with Science and Metaphysics but is already represented in 
"Empiricism and the Philosophy of Mind.") He denies, however, that Sellars is committed to the kind of guiding role for sense impressions which McDowell finds objectionable; on this point I disagree with him.

40. See note 13 and the associated text.

41. This idea, and the development of it that follows, draw on the view of synthesis as "exemplary of rules" which I presented in "Lawfulness without a Law" (1997) and then developed further, as the view that synthesis involves a "primitive" appreciation of normativity, in "Thinking the Particular as Contained under the Universal" (2006). The idea is pursued further, although in a contemporary rather than a Kantian context, in "Empirical Concepts and the Content of Experience" (2006a) and "Aesthetic Judgment and Perceptual Normativity" (2006b).

42. Here I am drawing on a point argued by both Strawson (1970) and Sellars (1978). Sellars illustrates it with the example of a red apple, perceived from one side, which is seen as having a red opposite side and a white volume of flesh inside even though these are not directly perceived: the red opposite side and the white inside are "present as actuality in the visual experience" not because they are seen, but rather by virtue of being imagined (1978, $\$ \$ 16-18,234-35)$. Strawson uses the example of a dog, which while silent and stationary, is seen as "a possible mover and barker" $(1970,40)$.

43. Manning argues, in reference to an earlier presentation of this account, that it cannot avoid ascribing "content" to the sensory representations which are associated in perceptual synthesis. "Surely [the representations] must have some particular distinguishing content, if it is to make sense to say that a natural disposition must associate some of these particular representations with some particular others. Associative dispositions must operate over features of the associated items even if they need not do so by means of some general rule. More basically, the representations over which dispositions operate must have some determinate features if it can be meaningfully said that the association groups distinct representations at all" $(2006,80)$. If this is correct, then my account is after all committed to a guiding, and not merely a causal, role for preconceptual sense impressions. But while I grant that such sense impressions must have determinate features, I do not think that this commits me to claiming that they have content in the relevant sense. My account can allow that sense impressions have distinctive phenomenological features which lead to their being associated one way rather than another: we might say that the kind of impression elicited by something green is phenomenologically distinct from the kind of impression elicited by something blue, and that that is why we are disposed to associate them differently. But we might equally well say that a pigeon's sense impressions have determinate phenomenological features responsible for their being associated in this or that determinate way, without taking this to imply that they have content, or correspondingly that they guide the pigeon by indicating how its sense impressions ought to be associated. Our sense impressions would indeed have content if, in addition to their having phenomenological features, we were aware of them as having these features; but that is not part of my account.

44. For more on this point, see my "Empirical Concepts and the Content of Experience" (2006a). It might be pointed out that the possibility which I am invoking - that a concept can figure in someone's experience without her possessing it antecedently to having the experience-is acknowledged by McDowell himself. For McDowell holds that the content of an experience can contain demonstrative concepts (say, the concept of a shade of color expressed by "that shade") which the subject does not possess prior to the experience but which are, rather, made possible by the experience itself (see his 1994, 56-60). But as far as I can tell McDowell appeals to this possibility only to address worries about the so-called fineness of grain of the content of experience, and does not take it, as I do, to apply in general to the concepts which figure in our experience.

45. Karl Ameriks makes the related point that "[p]erceiving something in a certain way can involve a concept even if it is not a matter of merely inferring from or subsuming under an already given concept" (2002, 313; he ascribes the point to Anthony Savile [1981, 364], but I find Ameriks's own statement of it clearer and also more closely related to my own view). Ameriks draws on this point to argue against my view, articulated elsewhere, that aesthetic perception for Kant is unlike cognitive perception in being nonconceptual. I regret having omitted to take his very interesting discussion into account in my recent (2006b) treatment of aesthetic and cognitive perception.

46. Patricia Kitcher makes a similar point when she describes McDowell as "offering an anodyne and 
redundant reading of 'spontaneous' as 'conceptual'” (1999, 424), although her alternative understanding of spontaneity differs from mine.

\section{REFERENCES}

Ameriks, Karl. 2003. “New Views on Kant's Judgments of Taste.” Originally published 1997; reprinted in Interpreting Kant's Critiques: 307-23. Oxford: Oxford University Press.

Beck, Lewis White. 1978. “Did the Sage of Königsberg Have No Dreams?” In Essays on Kant and Hume: 38-60. New Haven, Conn.: Yale University Press.

Davidson, Donald. 1986. "A Coherence Theory of Truth and Knowledge." In Truth and Interpretation: Perspectives on the Philosophy of Donald Davidson, ed. Ernest LePore. Oxford: Blackwell.

Forman, David. Forthcoming. "Learning and the Necessity of Non-Conceptual Content in Sellars's 'Empiricism and the Philosophy of Mind."' In The Self-Correcting Enterprise: Essays on Wilfrid Sellars, ed. M. P. Wolf and M. N. Lance. Amsterdam and New York: Rodopi.

Friedman, Michael. 1996. "Exorcising the Philosophical Tradition: Comments on John McDowell's Mind and World." Philosophical Review 105, 4: 427-67.

Ginsborg, Hannah. 1997. "Lawfulness without a Law." Philosophical Topics 25, 1. . 2006. "Thinking the Particular as Contained under the Universal." In Aesthetics and Cognition in Kant's Critical Philosophy, ed. Rebecca Kukla. Cambridge: Cambridge University Press.

. 2006a. "Empirical Concepts and the Content of Experience." European Journal of Philosophy 14, 4: 372-95.

2006b. "Aesthetic Judgment and Perceptual Normativity." Inquiry 49, 5: 1-35.

. Forthcoming. "Reasons for Belief." Philosophy and Phenomenological Research.

Hanna, Robert. 2001. Kant and the Foundations of Analytic Philosophy. Oxford: Oxford University Press.

. 2004. "Kant and Nonconceptual Content." European Journal of Philosophy 13, 2: 247-90.

Kant, Immanuel. 1902-. Gesammelte Schriften. Edited by the Prussian [now German] Academy of Sciences. Berlin: De Gruyter.

. 1929. Critique of Pure Reason. Translated by Norman Kemp Smith. London: Macmillan. - 1996. Critique of Pure Reason. Translated by Werner Pluhar. Indianapolis: Hackett.

. 1998. Critique of Pure Reason. Edited and translated by Paul Guyer and Allen Wood. Cambridge: Cambridge University Press.

Kitcher, Patricia. 1990. Kant's Transcendental Psychology. Oxford and New York: Oxford University Press.

. 1999. "Kant's Epistemological Problem and Its Coherent Solution." Philosophical Perspectives 13: 415-41.

Longuenesse, Béatrice. 1998. Kant and the Capacity to Judge. Princeton, N.J.: Princeton University Press.

Manning, Richard. 2006. “The Necessity of Receptivity.” In Aesthetics and Cognition in Kant's Critical Philosophy, ed. Rebecca Kukla. Cambridge: Cambridge University Press.

McDowell, John. 1994. Mind and World. Cambridge, Mass.: Harvard University Press. . 1996. Mind and World (paperback edition with new introduction). Cambridge, Mass.: Harvard University Press.

- 1998. "Having the World in View: Kant, Sellars and Intentionality" (The Woodbridge Lectures, 1997). Journal of Philosophy 95, 9: 431-91. . 2000. "Comments." Journal of the British Society for Phenomenology 31, 3: 330-43.

McGinn, Colin. 1984. Wittgenstein on Meaning. Oxford: Blackwell.

Okrent, Mark. 2006. "Acquaintance and Cognition." In Aesthetics and Cognition in Kant's Critical Philosophy, ed. Rebecca Kukla. Cambridge: Cambridge University Press.

Paton, H. J. 1936. Kant's Metaphysic of Experience. London: George Allen \& Unwin.

Pippin, Robert. 1982. Kant's Theory of Form. New Haven, Conn.: Yale University Press. . 2002. "Leaving Nature Behind." In Reading McDowell, ed. Nicholas H. Smith: 58-75. London and New York: Routledge.

Prauss, Gerold. 1971. Erscheinung bei Kant. Berlin: De Gruyter. 
Quine, Willard Van Orman. 1969. “Natural Kinds.” In Ontological Relativity and Other Essays. New York: Columbia University Press.

Savile, Anthony. 1981. "Objectivity in Kant's Aesthetic Judgment: Eva Schaper on Kant." British Journal of Aesthetics 21: 364-69.

Sellars, Wilfrid. 1956. "Empiricism and the Philosophy of Mind." In Minnesota Studies in the Philosophy of Science, Volume I, ed. Herbert Feigl and Michael Scriven. Minneapolis: University of Minnesota Press. 253-329.

. 1967. “Some Remarks on Kant's Theory of Experience." Journal of Philosophy 64, 20: 633-47. . 1968. Science and Metaphysics. London: Routledge and Kegan Paul.

- 1976. "Kant's Transcendental Idealism." In Proceedings of the Ottowa Congress on Kant. Ottowa: University of Ottowa Press, 165-81.

- 1978. "The Role of the Imagination in Kant's Theory of Experience." In Categories: A Colloquium, ed. Jr. Henry W. Johnstone: Department of Philosophy, The Pennsylvania State University.

Strawson, P. F. 1966. The Bounds of Sense. London: Methuen.

- 1970. "Imagination and Perception." In Experience and Theory, ed. Lawrence Foster and J. W. Swanson. Amherst: University of Massachusetts Press.

Stroud, Barry. 2002. "Sense-Experience and the Grounding of Thought." In Reading McDowell, ed. Nicholas H. Smith. London and New York: Routledge.

Walker, Ralph. 1985. "Synthesis and Transcendental Idealism." Kant-Studien 76: 14-27.

Wolff, Robert Paul. 1963. Kant's Theory of Mental Activity. Cambridge, Mass.: Harvard University Press. 